\title{
Neprilysin and A $\beta$ clearance: impact of the APP intracellular domain in NEP regulation and implications in Alzheimer's disease
}

\author{
Marcus O. W. Grimm ${ }^{1,2,3}$ *, Janine Mett ${ }^{1}$, Christoph P. Stahlmann ${ }^{1}$, Viola J. Haupenthal ${ }^{1}$, Valerie C. Zimmer ${ }^{1}$ \\ and Tobias Hartmann ${ }^{1,2,3}$
}

1 Experimental Neurology, Saarland University, Homburg, Saar, Germany

${ }^{2}$ Neurodegeneration and Neurobiology, Saarland University, Homburg, Saar, Germany

${ }^{3}$ Deutsches Institut für DemenzPrävention, Saarland University, Homburg, Saar, Germany

\section{Edited by:}

Roxana Octavia Carare, University of Southampton, UK

Reviewed by:

Roxana Octavia Carare, University of Southampton, UK

Anthony J. Turner, University of Leeds, UK

*Correspondence:

Marcus O. W. Grimm, Experimental Neurology, Saarland University, Kirrbergerstr. 1, Building 90, 66421 Homburg, Saar, Germany e-mail:marcus.grimm@uks.eu
One of the characteristic hallmarks of Alzheimer's disease (AD) is an accumulation of amyloid $\beta(A \beta)$ leading to plaque formation and toxic oligomeric $A \beta$ complexes. Besides the de novo synthesis of $A \beta$ caused by amyloidogenic processing of the amyloid precursor protein (APP), A $\beta$ levels are also highly dependent on $A \beta$ degradation. Several enzymes are described to cleave $A \beta$. In this review we focus on one of the most prominent $A \beta$ degrading enzymes, the zinc-metalloprotease Neprilysin (NEP). In the first part of the review we discuss beside the general role of NEP in A $\beta$ degradation the alterations of the enzyme observed during normal aging and the progression of $A D$. In vivo and cell culture experiments reveal that a decreased NEP level results in an increased $A \beta$ level and vice versa. In a pathological situation like $A D$, it has been reported that NEP levels and activity are decreased and it has been suggested that certain polymorphisms in the NEP gene result in an increased risk for AD. Conversely, increasing NEP activity in AD mouse models revealed an improvement in some behavioral tests. Therefore it has been suggested that increasing NEP might be an interesting potential target to treat or to be protective for AD making it indispensable to understand the regulation of NEP. Interestingly, it is discussed that the APP intracellular domain (AICD), one of the cleavage products of APP processing, which has high similarities to Notch receptor processing, might be involved in the transcriptional regulation of NEP. However, the mechanisms of NEP regulation by AICD, which might be helpful to develop new therapeutic strategies, are up to now controversially discussed and summarized in the second part of this review. In addition, we review the impact of AICD not only in the transcriptional regulation of NEP but also of further genes.

Keywords: Alzheimer's disease, Abeta degradation, neprilysin, AICD, amyloid beta, transcriptional regulation, Abeta clearance

\section{ALZHEIMER'S DISEASE}

Alzheimer's disease (AD) is one of the most common neurodegenerative disorders of the central nervous system. Currently more than 35 million people are affected worldwide and the number of affected people is estimated to double every 20 years leading to more than 115 million AD cases in the year 2050 (AD International, 2013). It is characterized by a degeneration of neurons in multiple brain regions, mainly the cortical and subcortical areas and hippocampus, leading to a loss of cognitive brain functions, memory impairment, and often to behavioral and physiological changes like apathy and depression. Characteristic histopathological hallmarks are intracellular neurofibrillary tangles composed of a hyperphosphorylated form of the microtubule-associated protein tau and extracellular $\beta$-amyloid plaques in brain tissue (Grundke-Iqbal et al., 1986; Selkoe, 2004; Binder et al., 2005). Major components of the $\beta$-amyloid deposits are hydrophobic amyloid- $\beta$-peptides $(\mathrm{A} \beta)$, which are 38-43 amino acids (aa) long fragments derived from proteolytic processing of the amyloid precursor protein (APP)
(Glenner and Wong, 1984; Masters et al., 1985; Aguzzi and Haass, 2003).

Most of the $\mathrm{AD}$ cases belong to the sporadic form of the disease with an onset after the age of 65 (late onset $\mathrm{AD}, \mathrm{LOAD}$ ). Less than $5 \%$ of all $\mathrm{AD}$ cases are genetically based (familial $\mathrm{AD}, \mathrm{FAD}$ ) due to mutations in the genes encoding for APP or presenilin 1 (PS1) and presenilin2 (PS2), proteins involved in the proteolytic cleavage of APP, leading to an earlier age of onset (Scheuner et al., 1996; Hardy, 1997). According to the amyloid cascade hypothesis, the excessive accumulation and aggregation of the $4 \mathrm{kDa} \mathrm{A} \beta$-peptide is regarded to be central in the pathogenesis of $\mathrm{AD}$, initiating cellular cascades leading to synaptic loss and neuronal injury (Hardy and Higgins, 1992; Hardy and Selkoe, 2002). Especially an increase in A $\beta 42$ (indicating $42 \mathrm{aa}$ ) is reported to trigger the disease process due to its high tendency to aggregate. Most of the FAD-linked mutations lead to an increase in total $A \beta$ levels or the ratio of $A \beta 42 / A \beta 40$ resulting in an aggressive and early occurring pathology (Kowalska, 2004; Duering et al., 2005). Accumulating evidence suggests 
that oligomeric $\mathrm{A} \beta$ species including dimers and trimers (Cleary et al., 2005; Shankar et al., 2007), small diffusible oligomers (Lambert et al., 1998), donut-like annular oligomers (Lashuel et al., 2002), and large amylospheroids (Hoshi et al., 2003) represent the most toxic forms of the peptide causing impaired synaptic and neuronal functions (Haass and Selkoe, 2007; Walsh and Selkoe, 2007).

The A $\beta$ levels in brain, are not only dependent on the de novo synthesis by APP processing, but also by its elimination via different mechanisms including its proteolytic degradation, transport processes, cell mediated clearance, and its deposition into insoluble aggregates. While enhanced $A \beta$ generation and a shift in the $\mathrm{A} \beta 40 / 42$ ratio have been shown to be associated with FAD, a diminished $A \beta$ clearance has been long hypothesized to predominate in LOAD (Tanzi et al., 2004; Hama and Saido, 2005). Indeed, recently a study by Mawuenyega et al. (2010) confirmed a significant impairment in the clearance of cerebrospinal fluid (CSF) $\mathrm{A} \beta$ in LOAD patients.

\section{APP AND THE GENERATION OF A $\beta$ THE APP FAMILY OF PROTEINS}

Amyloid precursor protein is a ubiquitously expressed type I integral transmembrane protein consisting of a large ectodomain, one single transmembrane domain, and a short intracellular tail (Kang et al., 1987; Dyrks et al., 1988). It belongs to a small gene family including the APP-like proteins 1 and 2 (APLP1 and APLP2) in mammals (Sprecher et al., 1993; Wasco et al., 1993), APL1 in C. elegans, APPL in D. melanogaster, and APPa and b in zebrafish (Musa et al., 2001). While APP and APLP2 are ubiquitously expressed, APLP1 expression is restricted to neurons (Tanzi et al., 1988; Slunt et al., 1994; Lorent et al., 1995). The gene encoding for human APP is located on chromosome 21 and contains 18 exons (Yoshikai et al., 1990). Alternative splicing of exons 7 and 8 generates APP mRNAs encoding for several isoforms, mainly APP770, APP751, and APP695 (referring to length in aa) with the latter being the major neuronal species (Sandbrink et al., 1994). While single knockout (KO) of one of the APP family members results only in viable mild phenotypes, APP/APLP2 double KO animals are perinatal lethal showing for example severe deficits in neuromuscular junctions (Wang et al., 2005a). Mice genetically deleted of all three APP gene family members show a neuronal ectopy in forebrain resembling the human type 2-lissencephaly, which also leads to animal death short time after birth (Herms et al., 2004). These severe phenotypes indicate important, partially overlapping physiological functions of APP, APLP1, and APLP2 in the mammalian nervous system (Aydin et al., 2012).

\section{PROTEOLYTIC PROCESSING OF APP}

Proteolytic processing of APP occurs via two different cleavage pathways and shows large homologies to the proteolytic processing of the Notch receptor as demonstrated in Figure 1.

In the case of the amyloidogenic processing pathway, APP is first cleaved within the extracellular domain by the transmembrane aspartyl protease BACE1 ( $\beta$-site APP cleaving enzyme 1 ) shedding off the soluble ectodomain $\mathrm{SAPP} \beta$ and generating the membranetethered C-terminal fragment (CTF) C99 (termed according to length in aa) (Vassar et al., 1999). In the case of the predominant non-amyloidogenic APP cleavage cascade the soluble ectodomain sAPP $\alpha$ and the C-terminal membrane-spanning stub C83 are generated by the activity of the $\alpha$-secretases, members of the ADAM (a disintegrin and metalloprotease) protein family (Lammich et al., 1999; Hooper and Turner, 2002). The $\alpha$-secretase cleavage site is located at position 16 within the $A \beta$ sequence, precluding the generation of $A \beta$ in the non-amyloidogenic pathway. The two alternative pathways are located in different subcellular compartments: while non-amyloidogenic APP processing, which is the major pathway of APP cleavage in all cells, takes place at the plasma membrane (Parvathy et al., 1999; Ehehalt et al., 2003), the amyloidogenic APP processing by $\beta$-secretase cleavage takes place in endosomes having a more acidic $\mathrm{pH}$, which is also the $\mathrm{pH}$ optimum of BACE1 mediated APP turn over (Grbovic et al., 2003; Carey et al., 2005; Rajendran et al., 2006).

The APP-CTFs are subsequently cleaved by $\gamma$-secretase liberating either the non-toxic peptide $\mathrm{p} 3$ (from $\mathrm{C} 83$ ) or $\mathrm{A} \beta$ (from C99) and the APP intracellular domain (AICD), which is discussed to regulate the expression of several genes, into the cytosol (Haass et al., 1992; Passer et al., 2000; Cao and Sudhof, 2004). The $\gamma$ secretase complex consists of at least four proteins, the proteins PS1 or PS2 as catalytic core, nicastrin, Aph (anterior pharynx defective) la or b, and presenilin enhancer 2 (PEN2) (Grimm et al., 2002; Baulac et al., 2003; Edbauer et al., 2003; Kimberly et al., 2003). It cleaves its substrates within the hydrophobic environment of the membrane, a process frequently involved in important signaling pathways and termed regulated intramembrane proteolysis (RIP) (Lichtenthaler et al., 2011). As $\gamma$-secretase cleavage can take place at different positions, $A \beta$ and AICD peptides vary in length. Since the major produced $A \beta$ species end at position 40 or 42 (Haass et al., 1992; Seubert et al., 1992; Roher et al., 1993; Iwatsubo et al., 1994), one can assume that AICD should begin at position 41 or 43 (aa numbers referring to the $\mathrm{A} \beta$ sequence). Contrary, most of the generated AICD seems to begin close to aa position 50 (Gu et al., 2001; Yu et al., 2001). This might be explained by the finding of another cleavage site of APP, termed $\varepsilon$-cleavage. It takes place not in the middle of the transmembrane domain of APP, but close to the cytoplasmic face of the plasmamembrane. Interestingly, $\varepsilon$-cleavage shares similarities to several other cellular proteolytic processes as for example the Notch-site-3 cleavage (Sastre et al., 2001; Weidemann et al., 2002). Presumably, processing of the CTF of APP at this cleavage site is carried out by the $\gamma$-secretase complex. It was shown that $\gamma$-secretase-inhibitors preventing $\mathrm{A} \beta 40$ and $\mathrm{A} \beta 42$ production also abolished AICD generation resulting from $\varepsilon$-cleavage. In addition to that, production of $\varepsilon$-cleaved AICD depends directly on the expression of PS1 (Yu et al., 2001). Up to now, the exact underlying mechanism how $\gamma$-secretase manages to cleave one single protein at different sites still has to be elucidated. It is discussed that cleavage occurs at aa 40 or 42 first, followed by aminopeptidase action on the 57 or 59 aa long AICD peptides, leading to the generation of truncated AICD (50-99 aa) (Gu et al., 2001; ChavezGutierrez et al., 2012). Another explanation is given by a model, in which APP is first cleaved at aa 49 or 50 resulting in the generation of AICD (50-99 aa) and the corresponding A $\beta$ counterparts $A \beta 1-$ 48 and $A \beta$ 1-49 (Qi-Takahara et al., 2005) which could possibly be further truncated by carboxypeptidase activity (Funamoto et al., 2004). The stepwise degradation of $A \beta$ then results in different 


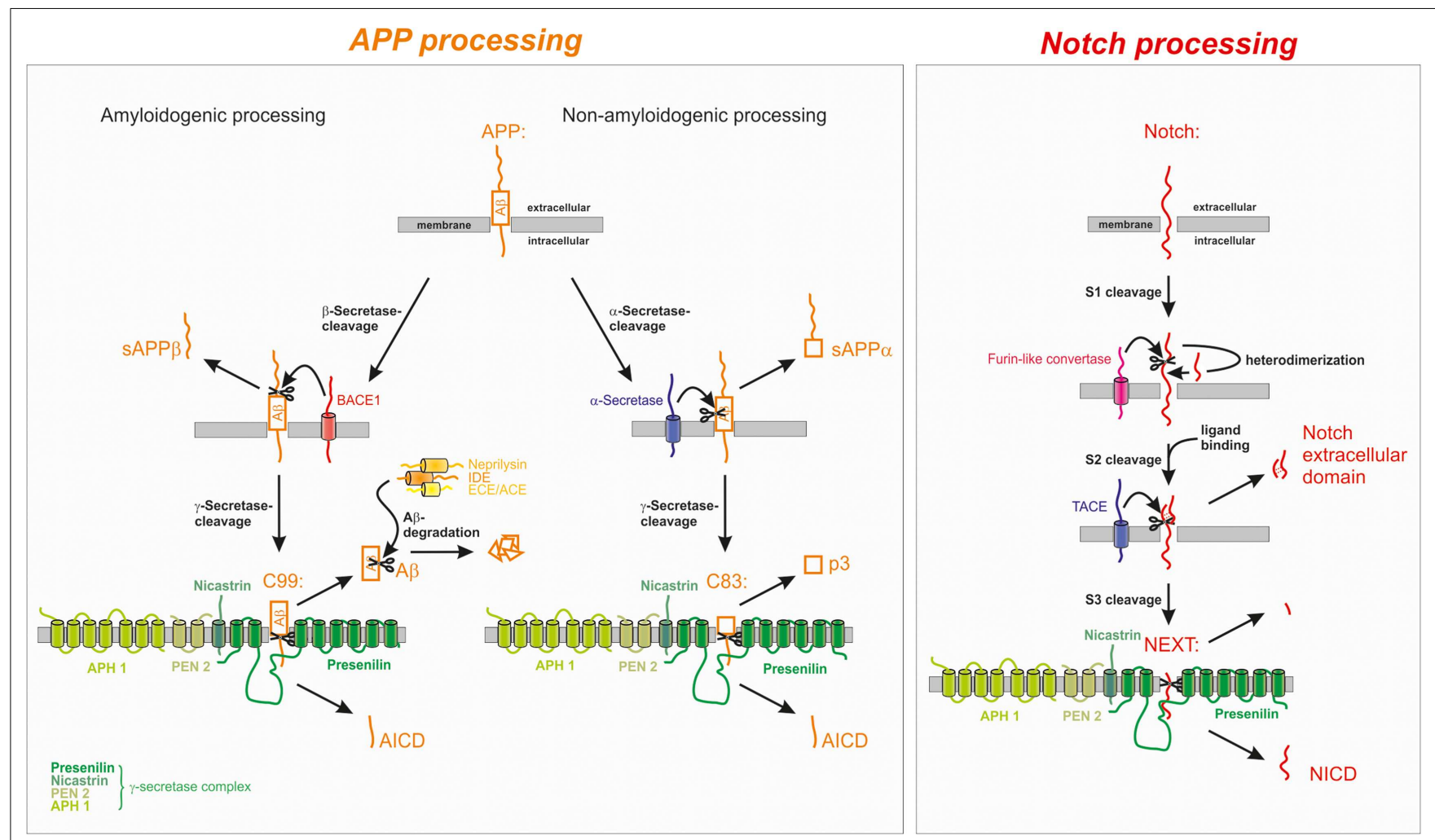

FIGURE 1 | Proteolytic processing of the amyloid precursor protein (APP) and Notch. APP processing: in the amyloidogenic processing pathway, APP is cleaved by the $\beta$-secretase BACE1 generating C99 which is further cleaved to the Amyloid- $\beta$ peptide $(A \beta)$. The non-amyloidogenic processing pathway is initiated by $\alpha$-secretase cleavage of APP within the $A \beta$ domain, thus precluding the generation of $A \beta . \alpha$ - and $\beta$-secretase cleavage releases the soluble forms of APP, sAPP $\alpha$, and SAPP $\beta$, respectively, into the extracellular space. The remaining membrane-bound C-terminal fragments C83 and C99 are further processed by the $\gamma$-secretase complex leading to the generation of the non-toxic p3 from $\mathrm{C} 83$ or of the amyloidogenic $A \beta$ peptide from $C 99$. A $\beta$ is rapidly degraded by several enzymes, for example neprilysin (NEP), insulin-degrading enzyme (IDE), endothelin-converting enzyme (ECE), and angiotensin converting enzyme (ACE). In both processing pathways the APP intracellular domain (AICD) is released into the cytosol. Notch processing: after maturation $\mathrm{S} 1$ cleavage of the Notch receptor precursor by a furin-like convertase, Notch is processed similarly to APP. Ligand binding triggers the $S 2$ cleavage by the $\alpha$-secretase TACE/ADAM17 leading to the release of the Notch extracellular domain into the extracellular space. The remaining membrane-bound fragment Notch extracellular truncation (NEXT) is further processed by the $\gamma$-secretase complex resulting in the release of the Notch intracellular domain (NICD) from the membrane.
A $\beta$ species (38-43 aa in length) (Chavez-Gutierrez et al., 2012). Alternatively, it is discussed that $\gamma$-secretase possibly cleaves APP simultaneously at several sites or that other proteases are involved in this process. Yu et al. (2001) proposed the model of a membraneresident, multicatalytic protease introducing non-selectively the cleavage of membrane proteins by resident enzymes. Caspase- 3 is also reported to truncate AICD and hence to produce the 31 aa peptide C31 (Gervais et al., 1999), which was shown to be elevated in $\mathrm{AD}$ brains and to be involved in cell death pathways (Lu et al., 2000).

The homologs APLP1 and APLP2, lacking the A $\beta$ region, are processed similarly to APP by $\alpha$-, $\beta$-, and $\gamma$-secretase cleavage generating the APLP intracellular domains ALID1 and ALID2 (Walsh et al., 2003; Eggert et al., 2004).

\section{THE A $\beta$ DEGRADING ZINC-METALLOPROTEASE NEPRILYSIN MECHANISMS OF A $\beta$ CLEARANCE IN BRAIN}

As already mentioned, the $A \beta$ levels in brain depend not only on $\mathrm{A} \beta$ production, but also on its removal via different clearance pathways and enzymatic degradation. Under physiological conditions the peptide is rapidly cleared from brain by a combination of several mechanisms, resulting in a half-life of approximately 1-2, 5 h (Savage et al., 1998; Cirrito et al., 2003). A $\beta$ can be exported from brain across the blood-brain-barrier by the lipoprotein receptor-related protein (LRP) and by the P-glycoprotein efflux pump (pgP/MDR1/ABCB1) (Kang et al., 2000; Shibata et al., 2000; Lam et al., 2001), whereas the reentry of circulating $A \beta$ from blood to brain is mainly mediated by RAGE (receptor for advanced glycation end products) (Deane et al., 2003). In plasma the peptide is bound by a soluble form of LRP (sLRP) and transported to liver and kidneys, which mediate the systemic clearance of unbound $A \beta$ and of sLRP-A $\beta$ complexes (Sagare et al., 2007, 2012). Furthermore, phagocytosis by microglia followed by lysosomal degradation and perivascular drainage along basement membranes into the CSF contributes to $A \beta$ removal from brain (Rogers and Lue, 2001; Preston et al., 2003). A diversity of enzymes is capable of cleaving $A \beta$ at a single or at multiple sites, most of them are metalloproteases differing in their regional and subcellular distribution, 
their $\mathrm{pH}$-optima and their ability to degrade the different species of the peptide (Miners et al., 2011; Saido and Leissring, 2012). Some $A \beta$ degrading enzymes are localized within the secretory pathway and catabolize intracellular $\mathrm{A} \beta$ prior to its secretion into the extracellular space (Eckman et al., 2001; White et al., 2006). $\mathrm{A} \beta 40$ is discussed to be mainly degraded intracellularly, whereas $\mathrm{A} \beta 42$ is basically degraded outside the cell (Hama et al., 2004). Therefore one might speculate that the different intra- and extracellular pools of $\mathrm{A} \beta$ are not removed by one single protease, but rather by several enzymes working cooperatively together (Saido and Leissring, 2012). A $\beta$ exists in a dynamic equilibrium of soluble monomeric, oligomeric, and fibrillar forms (Dahlgren et al., 2002). Fibrillization is dependent on the formation of $\beta$-sheet-structures between the residues 18 and 42 making this region less accessible to proteolytic cleavage (Crouch et al., 2009). Therefore, all known $\mathrm{A} \beta$ degrading enzymes are capable of cleaving monomeric $\mathrm{A} \beta$, but most of them show a restricted ability to degrade oligomeric or fibrillar species of the peptide. The proteolysis of $A \beta$ is generally assumed to be beneficial, but for most of the resulting products their neurotoxic potential or potential physiological relevance still has to be investigated.

\section{Summary}

$\mathrm{A} \beta$ levels in brain are influenced not only by $\mathrm{A} \beta$ production, but also by different clearance mechanisms including its clearance to blood and CSF, phagocytosis by microglia, and enzymatic degradation. The zinc-metalloprotease neprilysin (NEP) is one of the most prominent $A \beta$ degrading enzymes.

\section{GENERAL FEATURES OF NEP}

It has been shown that a neutral endopeptidase sensitive for thiorphan and phosphoramidon plays a key role in $\mathrm{A} \beta 42$ catabolism in rat brain, leading to the proposal that NEP is the major $A \beta$ degrading peptidase in vivo (Iwata et al., 2000). In line with these results NEP deficiency results in twofold elevated levels of endogenous $A \beta 40$ and $A \beta 42$ in different brain regions and in defects in the degradation of exogenously administered $A \beta 42$ (Iwata et al., 2001). Today NEP is one of the major and best characterized A $\beta$ degrading enzymes (Hersh and Rodgers, 2008).

Neprilysin is also named CALLA (common acute lymphocytic leukemia (ALL) antigen), enkephalinase, neutral endopeptidase 24.11, and CD10 antigen (Brown et al., 1974; Schwartz et al., 1980; Letarte et al., 1988). It belongs to the family of M13 zincmetalloendopeptidases and is an ubiquitously occurring type II integral membrane protein consisting of 742 aa with a molecular weight ranging from 85 to $110 \mathrm{kDa}$ depending on differences in its glycosylation (Relton et al., 1983; Malfroy et al., 1988). It is highly expressed in kidney, but also in other tissues like brain (Erdos and Skidgel, 1988). The active center of the enzyme faces the extracellular side of the membrane, an ideal topology for the degradation of peptides located in the extracellular space or associated to the membrane (Fukami et al., 2002).

The human NEP gene [MME, epicatechin (EC) 3.4.24.11] maps to chromosomal region $3 \mathrm{q} 25.1-\mathrm{q} 25.2$ and is composed of 24 exons, highly conserved among mammals (D'Adamio et al., 1989). The expression of the NEP gene is controlled by at least two different promoters and varies between different tissues. Alternative splicing in the $5^{\prime}$-untranslated region results in four separate mRNA transcripts without affecting the coding region (Li et al., 1995). The protein consists of a short N-terminal cytosolic region, a single transmembrane helix and a large extracellular domain containing the typical HEXXH zinc binding motif that is essential for the proteolysis of its various substrates described below (Barnes et al., 1995; Turner et al., 2001), preferentially oligopeptides consisting of up to 40 aa (Oefner et al., 2000). NEP is involved in neuropeptide signaling and in the regulation of vascular tone (Roques et al., 1993). Moreover, it is used as an important cellsurface marker in the diagnosis of human acute lymphocytic leukemia (ALL) (Brown et al., 1975) and reported to play a role in the progression of several other cancers (Gohring et al., 1998; Papandreou et al., 1998). In the central nervous system NEP is mainly expressed by neurons (Matsas et al., 1986), but also by activated astrocytes and microglia (Fisk et al., 2007; Hickman et al., 2008). In neurons NEP is subcellularly localized along axons and synapses (Fukami et al., 2002) where NEP mediated A $\beta$ degradation mainly takes place (Barnes et al., 1992; Hama et al., 2001; Iwata et al., 2004). This subcellular localization underlines the role of NEP in the degradation of several neuropeptides, for example enkephalins, substance P, neuropeptide Y, tachykinins, bradykinin, and somatostatin (Matsas et al., 1984; Roques et al., 1993; Barnes et al., 1995). The in vivo functions of NEP have been analyzed by utilizing NEP gene disrupted mice. These animals show enhanced lethality to endotoxin treatment, probably due to the role of NEP in the metabolism of pro-inflammatory peptides, lower blood pressure, and higher microvascular permeability (Lu et al., 1995).

\section{Summary}

Neprilysin is an $85-110 \mathrm{kDa}$ zinc-dependent membrane metalloprotease degrading numerous extracellular located substrates, among them $\mathrm{A} \beta$ and several neuropeptides. The enzyme is expressed in various tissues including the central nervous system, where it is mainly present in neurons with a subcellular localization along axons and synapses.

\section{NEP AND ITS FUNCTION IN A $\beta$ DEGRADATION}

The ability of NEP to cleave $A \beta$ monomers in vitro as well as in cell culture was analyzed in different studies (Howell et al., 1995; Hama et al., 2001; Kanemitsu et al., 2003; Marr et al., 2003). It is worth mentioning that NEP is reported to cleave monomeric $\mathrm{A} \beta 40$ more efficiently than $A \beta 42$. In an in vitro degradation assay only $27 \%$ of the added monomeric $A \beta 42$ was degraded by NEP, in contrast the enzyme cleaved $73 \%$ of the added $A \beta 40$ monomers (Kanemitsu et al., 2003). In the meantime several cleavage sites of NEP within the $A \beta$ sequence have been identified (Carson and Turner, 2002; Wang et al., 2006; Miners et al., 2011), which are summarized in Figure 2. The ability of the enzyme to degrade $A \beta$ oligomers and fibrils is controversially discussed, e.g., NEP seems to be capable of degrading synthetic oligomers formed non-enzymatically from synthetic $A \beta 40$ and $A \beta 42$ (Kanemitsu et al., 2003), but not oligomers naturally secreted from cells (Leissring et al., 2003).

Interestingly, some of the pathogenic APP mutations result in a higher resistance of $A \beta$ to NEP-catalyzed proteolysis. Tsubuki et al. incubated wildtype $A \beta 40$ and $A \beta 40$ peptides containing the Dutch, Flemish, Italian, and Arctic mutation (Van Broeckhoven 


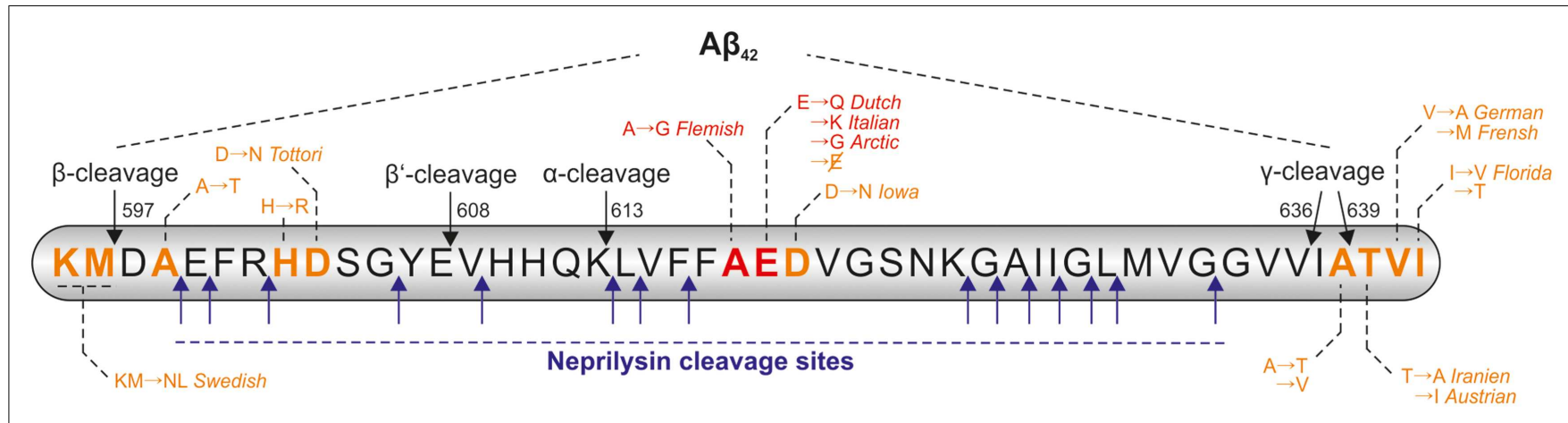

FIGURE 2 | Cleavage sites of NEP within the A $\beta$-sequence and positions of FAD mutations. Within the $A \beta$ sequence there are several cleavage sites for neprilysin (NEP), the cleavage positions of $\alpha-, \beta-$, and $\gamma$-secretase are also indicated. Some of the pathological point mutations within the $A \beta$ sequence are reported to result in a higher resistance of the peptide to NEP-catalyzed proteolysis (highlighted in red), other known mutation sites are shown in orange. The amino acid numbers are referring to the APP695 isoform. et al., 1990; Hendriks et al., 1992; Nilsberth et al., 2001; Bugiani et al., 2010) (indicated in Figure 2) with purified mouse NEP prior to analysis of the peptides by high-performance liquid chromatography (HPLC). All mutated $\mathrm{A} \beta$ peptides were more resistant to NEP-catalyzed cleavage in comparison to wildtype A $\beta 40$ (Tsubuki et al., 2003). Betts et al. analyzed the same peptides and found significant differences in their tendency to aggregate. Furthermore, they demonstrated aggregated wildtype $A \beta 40$ to be less well degraded than its monomeric form. Proteolysis analysis of the mutated monomeric peptides by HPLC revealed that all mutated $\mathrm{A} \beta$ species with exception of the Flemish mutated peptide are degraded equally well by NEP as wildtype $A \beta$. Only $A \beta$ bearing the Flemish mutation was degraded significantly more slowly by NEP. The authors concluded, that the most likely explanation for this divergence in results lies in differences in the aggregation state of the analyzed peptides (Betts et al., 2008).

The in vivo function of NEP in $\mathrm{A} \beta$ degradation reported by Iwata et al. has been verified in several other studies. It was demonstrated that intraneuronal $\mathrm{A} \beta 42$ deposits and $\mathrm{A} \beta 42$ induced neuronal loss can be sufficiently suppressed in transgenic $D$. melanogaster expressing human NEP and A $\beta 42$ (Iijima-Ando et al., 2008). Moreover, KO of NEP in mice result in an increase in the levels of soluble and oligomeric $A \beta$ leading to impaired synaptic plasticity and cognitive abnormalities in APP transgenic and wildtype animals (Huang et al., 2006; Madani et al., 2006). Conversely, overexpression of NEP in AD mouse models by using either genetic or viral approaches leads to decreased cerebral $A \beta$ levels, inhibition of plaque formation, and enhanced life expectancy (Leissring et al., 2003; Marr et al., 2003; Iwata et al., 2004; Poirier et al., 2006). In line with this, improved behavioral performance and cognitive functions in the NEP overexpressing animals is reported (Poirier et al., 2006; El-Amouri et al., 2008; Spencer et al., 2008). Recently, Iwata et al. (2013) demonstrated the AAV vector-mediated NEP gene transfer into an $\mathrm{AD}$ mouse model to significantly reduce monomeric, dimeric, trimeric, and tetrameric forms of $A \beta$ accompanied by alleviation of abnormal learning and memory function. Further, the administration of recombinant soluble NEP by intracerebral injection into AD mice was reported to result in significantly reduced accumulation of $A \beta$ and additionally in improved behavioral performance on the water maze test (Park et al., 2013). Conversely, Meilandt et al. (2009) failed to assess behavioral improvement in the Morris water maze test and reduction of $\mathrm{A} \beta$ oligomers in hAPP/NEP double transgenic animals despite $50 \%$ reduction in soluble $A \beta$ levels and prevention of plaque formation, demonstrating the inability of NEP to cleave some naturally occurring oligomeric $\mathrm{A} \beta$ species.

Furthermore, NEP is discussed to be a genetic risk factor for the development of AD. It has been demonstrated that individuals with certain polymorphisms in the NEP gene have an increased risk for $\mathrm{AD}$ (Helisalmi et al., 2004) and the susceptibility to $\mathrm{AD}$ is even higher when insulin-degrading enzyme (IDE), another $\mathrm{A} \beta$-degrading enzyme, also shows a polymorphism (Vepsalainen et al., 2009). In contrast, other studies reported a lack of association between NEP polymorphisms and the risk for developing AD (Sodeyama et al., 2001; Oda et al., 2002; Wood et al., 2007).

\section{Summary}

While NEP is capable to cleave $\mathrm{A} \beta$ monomers in vitro and in vivo, its ability to degrade oligomeric $\mathrm{A} \beta$ species is controversially discussed. Decreased NEP levels were shown to result in increased A $\beta$ levels, impaired synaptic plasticity, and cognitive abnormalities in WT and APP transgenic mice. Conversely, enhanced NEP levels in $\mathrm{AD}$ mouse models lead to reduced $\mathrm{A} \beta$ levels accompanied by an improvement in some behavioral tests.

\section{ALTERED NEP REGULATION IN AGING AND AD}

As already mentioned, defective $A \beta$ clearance has been long hypothesized to predominate in LOAD. Therefore, a possible correlation of NEP levels with the progression of $\mathrm{AD}$ and with normal aging has been intensively investigated.

\section{REDUCTION OF NEP LEVELS IN AD}

In general, NEP seems to be reduced in brain areas early affected in $\mathrm{AD}$ and characterized by extensive plaque load. NEP levels are decreased in hippocampus (Yasojima et al., 2001a; Carpentier et al., 2002; Miners et al., 2006), temporal gyrus (Yasojima et al., 2001b), and cortex (Akiyama et al., 2001; Russo et al., 2005; Wang et al., 2005b; Miners et al., 2006) in human post mortem AD brains. 
$\mathrm{NEP}$ is also reduced in brain vasculature of $\mathrm{AD}$ patients (Carpentier et al., 2002; Miners et al., 2006) implicating a role of NEP in cerebral amyloid angiopathy (CAA). Moreover, alterations in NEP expression in $\mathrm{AD}$ are not restricted to brain tissue since the enzyme level was found to be also affected in CSF. In patients with mild cognitive impairment (MCI), substantial reduction of CSF NEP activity was observed followed by an elevation along with the progression of $\mathrm{AD}$, suggesting that presynaptically located NEP is released into CSF as a consequence of synaptic disruption (Maruyama et al., 2005). An inverse relationship between NEP levels and $\mathrm{A} \beta$ accumulation has been shown in temporal and frontal cortex (Hellstrom-Lindahl et al., 2008) and in the vasculature (Carpentier et al., 2002) of human AD patients as well as in the hippocampus of APP transgenic mice (Fukami et al., 2002), indicating that even a slight reduction in NEP levels for several decades can lead to increased $A \beta$ levels. However, other studies reported NEP levels in cortex not to be significantly altered (Hellstrom-Lindahl et al., 2008), or even elevated (Miners et al., 2009) in human post mortem AD brains compared to control brains. In the latter study NEP protein levels and activity, which was measured by the use of a highly specific immunocapture-based fluorometric activity assay (Miners et al., 2008), were reported to positively correlate with Braak stage. Interestingly, in this study NEP level was normalized to a protein marker for neuronal integrity, the neuron specific enolase (NSE). Moreover, quite recently Zhou et al. (2013) reported a decrease of NEP levels in cytoplasm and in contrast an increase in membrane fractions of MCI and AD brains indicating an altered subcellular localization of NEP in AD, which might also explain differences found in literature. Keeping in mind that NEP is a plasma membrane ectoenzyme, the detection of apparently cytoplasmatic NEP in this study is questionable and might possibly be an artifact resulting from the extraction process. In astrocytes the expression of NEP is upregulated in $\mathrm{AD}$, especially in plaque-surrounding reactive astrocytes as demonstrated for aged APPswe mice (Apelt et al., 2003) and for human AD brains (Carpentier et al., 2002), further suggesting a possible role of astrogliosis in $\mathrm{A} \beta$ degradation.

Possible explanations for this divergence in results are for example methodological differences, differences in the analyzed brain areas, cell types and in sample preparation. Moreover, there are severe difficulties in specifically measuring NEP activity which could lead to different results. Taking in consideration that possibly a late upregulation of NEP in association with disease progression exists, difference in disease state of the analyzed individuals is a critical point for comparing the results of several studies. Additionally, indication exists that normal aging processes can also result in a reduction of NEP further underlying the importance of comparing stringently age matched controls to post mortem $\mathrm{AD}$ brains.

\section{Summary}

Neprilysin seems to be reduced in brain areas early affected in AD and characterized by high plaque load. A decline of NEP levels in $\mathrm{AD}$ has been observed in most of the studies although some authors assessed converse results.

\section{REDUCTION OF NEP LEVELS DURING AGING}

Several studies reported significant reductions of brain NEP levels in aged animals and human beings. NEP mRNA levels decline during aging in D. melanogaster brains (Iijima-Ando et al., 2008), similar effects were observed in mammals. NEP levels or enzyme activity diminish as a function of age in mouse cerebral cortex (Apelt et al., 2003), hippocampus (Caccamo et al., 2005), in whole mouse brain homogenate (Carter et al., 2006), and in the hippocampus of aged rats (Briones and Darwish, 2012). Iwata et al. (2002) further demonstrated by immunohistochemical analysis of the hippocampus of APP transgenic mice that NEP levels are selectively decreased in nerve terminals and axons upon aging. In line with these observations, a negative correlation between brain NEP levels and age was reported for both non-demented persons and AD patients (Russo et al., 2005; Hellstrom-Lindahl et al., 2008; Miners et al., 2009).

\section{Summary}

Neprilysin levels seem to be reduced during aging as demonstrated in aged $D$. melanogaster, mice, rats, and human beings.

\section{MECHANISMS OF NEP REGULATION}

Taking into consideration that NEP expression and activity seem to be reduced in $\mathrm{AD}$, it can be speculated that increased upregulation of NEP might have beneficial effects. The pathways involved in the regulation of NEP expression and activity possess an attractive therapeutic potential and have been further elucidated. Saito et al. reported that the neuropeptide somatostatin, which is a NEP substrate (Barnes et al., 1995), is able to upregulate NEP activity indicating a regulatory feedback cycle. Treatment of primary neurons with somatostatin results in a higher, somatostatin deficiency in mice in a reduced NEP activity, respectively (Saito et al., 2005). Pharmacological activation of the somatostatin receptor subtype- 4 increases NEP activity in cortical tissue, suggesting that the somatostatin receptors are interesting pharmacological targets for the regulation of enzyme activity (Sandoval et al., 2012). In addition, NEP expression can be upregulated by the hormone estrogen in an estrogen receptor $\alpha$ and $\beta$ dependent manner in human SH-SY5Y cells (Liang et al., 2010). A decrease of NEP activity combined with elevated brain $A \beta$ levels were observed in ovariectomized animals with estrogen treatment reversing the effects (Petanceska et al., 2000; Huang et al., 2004). We and others have shown the secosteroid vitamin $\mathrm{D}$ to be involved in the regulation of NEP in vitro and in vivo. Vitamin $\mathrm{D}$ deficiency in mice results in a lowered NEP expression and enzyme activity, while vitamin D supplementation elevates NEP levels in cultured cells and in the brain of aged rats (Briones and Darwish, 2012; Grimm et al., 2013). The reported downregulation of somatostatin (Davies et al., 1980; Lu et al., 2004; Gahete et al., 2010), estrogen (Manly et al., 2000; Barron and Pike, 2012), and vitamin D (Annweiler et al., 2011; Llewellyn et al., 2011) in aged individuals and AD patients may explain the downregulation of NEP upon aging and in AD. Furthermore, oxidative stress, which is increased in $\mathrm{AD}$ brain, leads to decreased half-life of NEP and decreased enzyme activity (Wang et al., 2003; Shinall et al., 2005). Oxidative stress initiates the formation of 4-hydroxy-non-enal (HNE), a by-product of lipid peroxidation reported to be increased in $\mathrm{AD}$ brains, interacting with, and inactivating a variety of enzymes including NEP (Lauderback et al., 2001; Wang et al., 2003). In cell culture studies using SK-N-SH cells, green tea extract (Melzig 
and Janka, 2003), and more specifically the antioxidative green tea polyphenols EC, epigallocatechin (EGC), and epigallocatechin gallate (EGCG) among other components increase cellular NEP activity (Ayoub and Melzig, 2006). In 2011 the small neuroprotective peptide humanin, whose cDNA was found in an AD patients brain (Hashimoto et al., 2001), was shown to increase NEP expression in the hippocampus of an AD mouse model (Niikura et al., 2011). Kynurenic acid (KYNA), one of the main products of the kynurenine pathway, is another neuroprotective component that is able to increase NEP expression, protein levels and activity in cultures of human neuroblastoma SH-SY5Y cells and mouse cortical neurons (Klein et al., 2013).

\section{Summary}

Several naturally occurring compounds, e.g., somastatin, estrogen, vitamin $\mathrm{D}$, and components of green tea are able to upregulate NEP expression and/or activity. In contrast, oxidative stress was shown to lower the half-life and activity of the enzyme.

Most discussed in the last years is the regulation of NEP expression by AICD in a Notch-like signaling pathway.

\section{AICD NUCLEAR SIGNALING AND ITS IMPACT ON THE REGULATION OF NEP}

STRIKING SIMILARITIES BETWEEN NOTCH AND APP PROCESSING

Like APP, the Notch receptors are single-pass type I transmembrane proteins that are processed with some striking similarities to APP (shown in Figure 1). In response to an extracellular signal, Notch is sequentially cleaved within its extracellular domain followed by intramembrane cleavage and the release of an extraand intracellular fragment.

During maturation S1 cleavage of the Notch receptor precursor by a furin-like convertase takes place in the Golgi network and the fragments are shuttled to the cell surface as a non-covalently linked heterodimeric receptor molecule (Kopan and Turner, 1996; Logeat et al., 1998). The extracellular domain of Notch contains epidermal growth factor (EGF)-like repeats which mediate the binding of DSL ligands (Delta, Serrate/Jagged). This initiates S2 cleavage of Notch catalyzed by a member of the ADAM/tumor necrosis factor$\alpha$-converting enzyme (TACE) metalloprotease family releasing the Notch extracellular domain and the transient intermediate peptide Notch extracellular truncation (NEXT) (Mumm et al., 2000). In contrast to Notch processing there is no equivalent APP maturation and ligand binding necessary for APP to be further processed. Like the APP CTFs, NEXT is a substrate for the multimeric $\gamma$ secretase enzyme complex cleaving NEXT in its intramembrane region (De Strooper et al., 1999; Sastre et al., 2001). The $\gamma$-secretase mediated S3 cleavage of NEXT, which shares similarities with the $\gamma$-/ $\varepsilon$-cleavage of APP CTFs regarding the membrane topology, presenilin-dependence, cleavage before a valine residue, and inhibition profile (Weidemann et al., 2002), releases the mobile cytoplasmic subunit Notch intracellular domain (NICD) from the membrane (Schroeter et al., 1998). NICD migrates to the nucleus and heterodimerizes with CSL (CBF1-SU(H)-LAG1) (Schroeter et al., 1998), which represses Notch target genes through recruitment of corepressor complexes in the absence of AICD. NICD displaces these corepressors, recruits a coactivator complex, and hence activates transcription. A role of NICD in the transcriptional regulation of several genes is well established (Borggrefe and Oswald, 2009). Due to the obvious similarities between APP and Notch in their protein structure and proteolytic cleavage, it is reasonable to assume that APP takes part in the regulation of other genes via its intracellular domain as well. Such a function of AICD is controversially discussed.

\section{Summary}

The high similarities between APP and Notch receptor processing by ADAM and $\gamma$-secretase activity leading to the generation of a large ectodomain and a short intracellular fragment indicate that AICD is likely to regulate the expression of multiple genes similar to NICD.

\section{THE MECHANISMS OF AICD NUCLEAR SIGNALING}

Within AICD there are several sequence motifs of functional relevance which are summarized in Figure 3, e.g., the ${ }^{653} \mathrm{YTSI}$ sequence, the ${ }^{667}$ VTPEER sequence, and the ${ }^{681}$ GYENPTY motif with the aa numbers referring to the APP695 isoform. Tyr653 in the YTSI sequence is required for basolateral sorting of APP in polarized MDCK cells (Lai et al., 1998). The VTPEER site appears to be involved in pathophysiology and Thr668 is the major phosphorylation site of APP (Suzuki and Nakaya, 2008). Far more attention has been addressed to the GYENPTY sequence which includes a NPXY motif serving as internalization signal for membrane proteins (Chen et al., 1990) and interacting with adapter proteins containing a phosphotyrosine-binding (PTB) domain (Uhlik et al., 2005). Interestingly, the residue Tyr682 is essential for the function of APP in developmental processes. Barbagallo et al. (2011) showed expression of APP with the Y682G mutation in APLP2-KO mice not to be able to compensate the early postnatal lethality and neuromuscular synapse defects of APP/APLP2-KO mice.

After first description of AICD (then termed AID) by Passer et al. (2000), early experiments regarding a potential function of AICD in gene transcription were carried out by Cao and Sudhof in 2001 by using fusion proteins of APP and the DNA binding domains of the transcription factors Gal4 and LexA in combination with Gal4 and LexA dependent reporter plasmids to measure transactivation of transcription. Coexpression of the fusion proteins with the reporter plasmids resulted in only minor transactivation of transcription in HEK293, COS7, and HeLa cells, indicating that APP may need binding of a cofactor. Fe65 was identified as the major protein interacting with the APP cytoplasmic tail by yeast two-hybrid screens. Indeed, cotransfection of Fe65 and the APP-Gal4 or APP-LexA fusion proteins greatly stimulated transcription showing Fe65 to be the cofactor required for the function of AICD in gene regulation. Further yeast twohybrid assays revealed an interaction of Tip60 with the PTB1 site of Fe65. GST-Tip60 efficiently pulled down APP together with Fe65 indicating the existence of a stable trimeric complex composed of the APP cytoplasmic tail, Fe65 and Tip60 that is able to transactivate transcription in vitro (Cao and Sudhof, 2001). The members of the Fe65 protein family, Fe65 and the Fe65 like proteins 1 and 2 (Fe65L1 and Fe65L2) are multidomain adaptor proteins that form multiprotein complexes. They all have a WW domain and two PTB domains and bind to AICD via their PTB2 


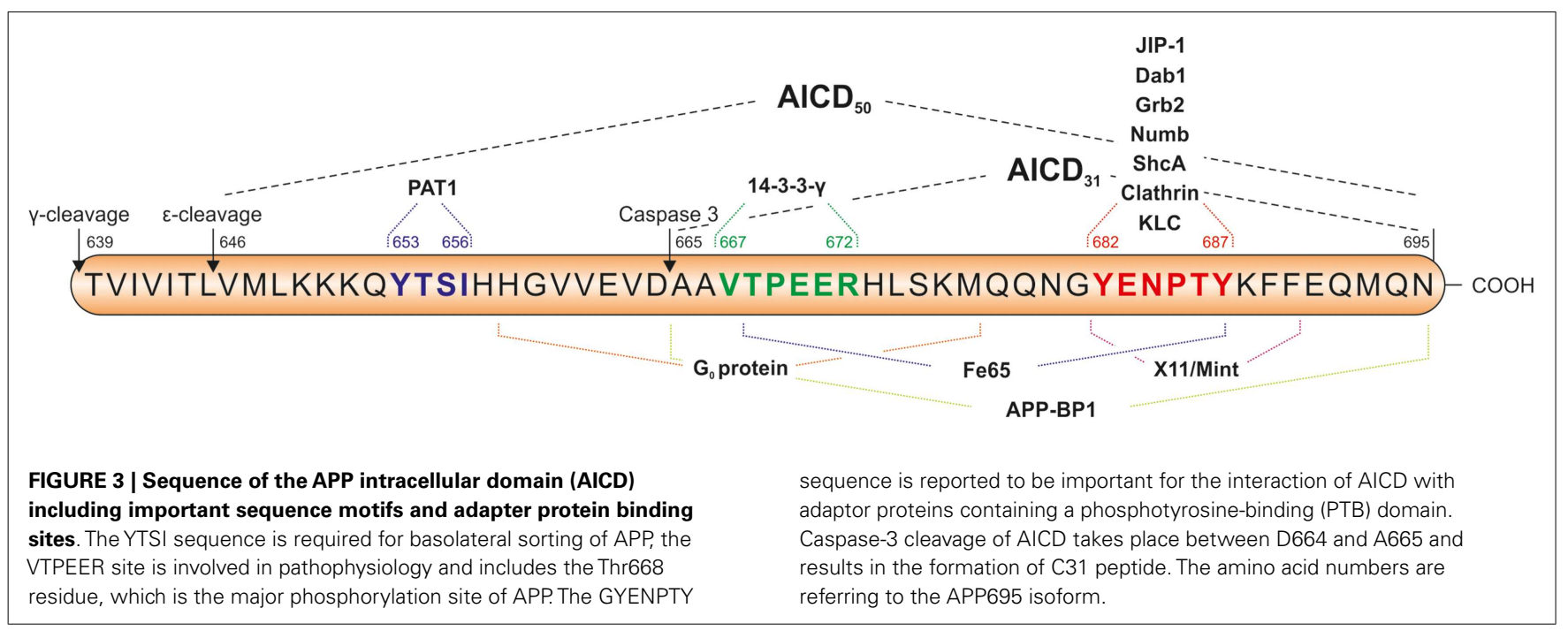

domain (McLoughlin and Miller, 2008). Fe65 increases the stability of AICD (Kimberly et al., 2001; Kinoshita et al., 2002), which has a reported half-life of not more than 5 min (Cupers et al., 2001) due to its rapid degradation in the cytosol by IDE (Edbauer et al., 2002; Farris et al., 2003), the proteasome (Nunan et al., 2003), and the endosomal/lysosomal protease Cathepsin B (Vingtdeux et al., 2007; Asai et al., 2011) enabling AICD to translocate to the nucleus (see Figure 4). Further, the importance of Fe65 in APP function in vivo is indicated by the phenotype of Fe65/Fe65L1 gene deleted mice, showing cortical dysplasia like APP/APLP1/APLP2 triple KO animals (Guenette et al., 2006). Tip60 is a histone acetyltransferase (Yamamoto and Horikoshi, 1997) acting in chromatin remodeling, DNA repair, transcription, and apoptosis (Ikura et al., 2000). The existence of the trimeric protein complex consisting of fluorescent protein-tagged AICD, Fe65, and Tip60 (termed AFTcomplex) was further confirmed by colocalization of the three proteins in spherical nuclear spots (Von Rotz et al., 2004; Goodger et al., 2009). Moreover, Konietzko et al. (2010) demonstrated by confocal analysis that nuclear export blockade allows to reveal the nuclear localization of endogenous AICD at the level of nuclear transcription territories.

All these observations resulted in the model that Fe65 binds AICD after its release from the membrane by $\gamma$-secretase cleavage, followed by the translocation of the Fe65/AICD complex to the nucleus, where it associates with Tip60 leading to the formation of AFT complexes. Although this model is suggested by most authors, there are some studies suggesting alternative mechanisms for signal transduction by APP (Muller et al., 2008). These models suggest an independent translocation of AICD and Fe65 to the nucleus (Nakaya and Suzuki, 2006), a conformational change of Fe65 induced by AICD enabling it to translocate to the nucleus where it binds Tip60 to form a transcriptionally active AFT complex (Cao and Sudhof, 2004), or the recruitment of Tip60 through Fe65 by the APP C-terminus independently from $\gamma$-secretase cleavage that results in the phosphorylation, stabilization and activation of Tip60 by cyclin-dependent kinase (CDK) leading to the translocation of the Tip60/Fe65 complex into the nucleus (Hass and
Yankner, 2005). Arguing against some of these alternative models, the translocation of AICD to the nuclear compartment was reported by several studies. AICD was found to be located in the nuclei of cultured cells and even in cortices of APP transgenic mice (Chang et al., 2006).

Alternatively to Tip60, the transcription factor CP2/LSF/LBP1 can interact with Fe65 and bind to the promoter region of potential AICD target genes (Zambrano et al., 1998; Kim et al., 2003). MED12 protein, which is part of the Mediator complex, a large protein complex transducing signals from specific transcription factors to RNA polymerase II, binds to Fe65 and Tip60 in the presence of AICD, providing a direct link of the AICD/Fe65/Tip60 complex to the RNA polymerase II general transcription apparatus (Xu et al., 2011).

More than 20 other adaptor proteins that bind AICD or the Fe65-AICD complex have been identified (Borquez and GonzalezBillault, 2012) (see Figure 3), the most prominent examples are reviewed here. Nuclear signaling of APP is prevented by MINT$1 / \mathrm{X} 11 \alpha$ by retaining AICD in the cytosol instead of translocating it to the nucleus (Von Rotz et al., 2004). The protein Dexras1 was shown to bind to the PTB2 domain of Fe65 and to compete with APP for binding to Fe65 leading to a suppression of FE65-APP mediated transcription (Lau et al., 2008). Interaction of AICD with the ubiquitin-like Nedd8 results in the dissociation of AICD from Fe65 combined with the reduction of AFT complexes and of AICD transcriptional activity (Lee et al., 2008). In contrast, the Janus kinase interacting protein-1 (JIP-1) in combination with AICD can activate gene expression in a Fe65 independent manner (Scheinfeld et al., 2003), with transport of AICD to nuclei and the subsequent docking to Tip60 resulting in the formation of AICD-JIP-1-Tip60 (AJT) complexes showing a different, speckle like morphology compared to AFT complexes (Von Rotz et al., 2004). Dimeric 14-3-3 $\gamma$ binds to the VTPEER sequence of AICD and to a sequence between the WW domain and the first PTB domain of Fe65 and facilitates gene transactivation by enhancing the AICD-Fe65-association (Sumioka et al., 2005). The phosphorylation status of AICD affects the affinity of binding partners 


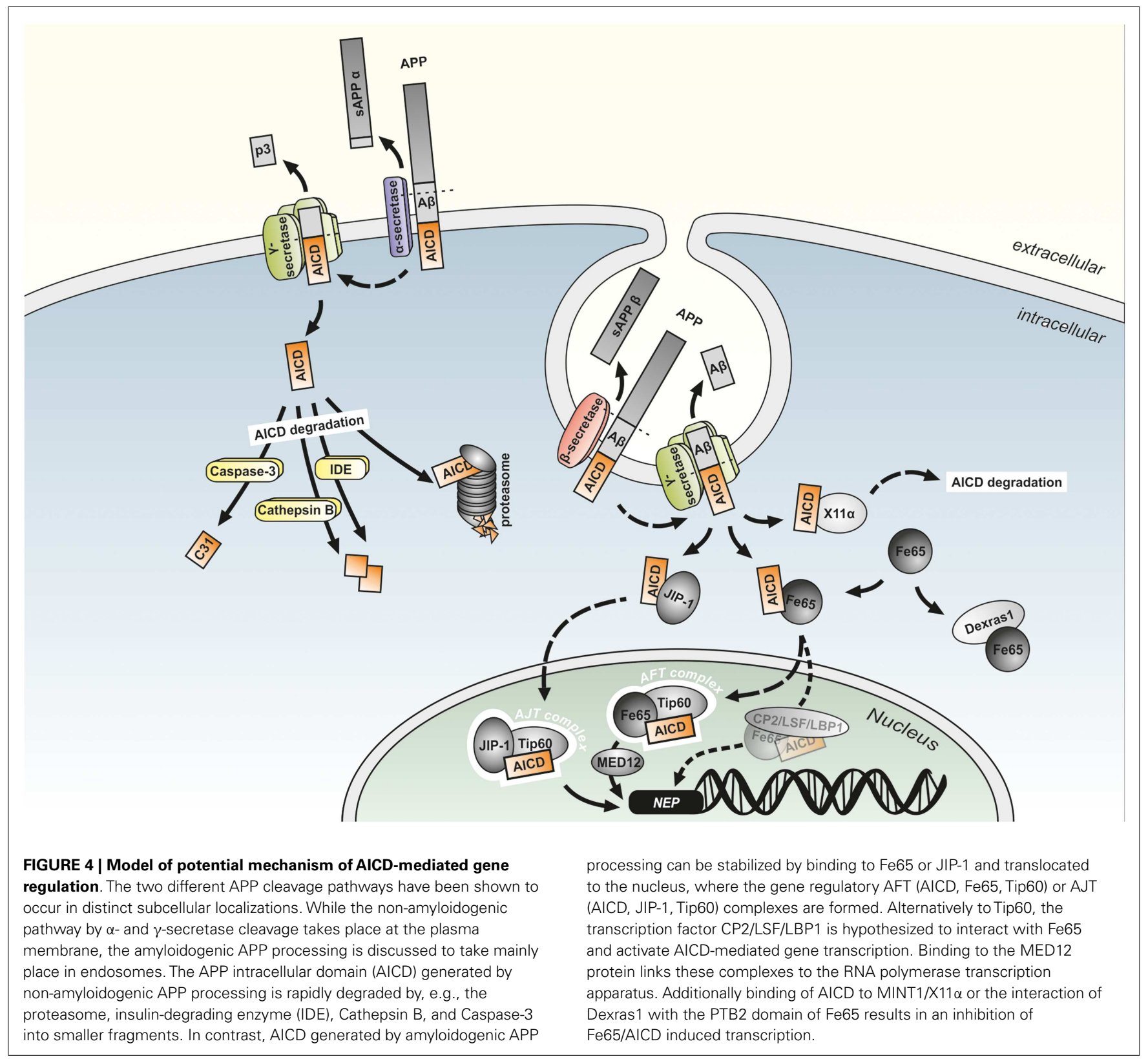

and therefore influences the Fe65/AICD-mediated transcriptional control (Ando et al., 2001).

Experimental evidence suggests that not all pools of AICD are active in nuclear signaling. As $\mathrm{A} \beta$, sAPP $\beta$ and AICD are mainly formed from APP695, this isoform mainly expressed in neurons seems to have a higher affinity or turnover by $\beta$-secretase compared to the other isoforms. In line, APP751 and APP770 were shown to be mainly processed by $\alpha$ - and $\gamma$-secretase cleavage (Kametani et al., 1993; Belyaev et al., 2010). Only the overexpression of APP695 results in an increase of AICD levels in nuclear fractions of SH-SY5Y cells (Belyaev et al., 2010). This may indicate a neuronal specificity of the AICD-mediated gene regulatory mechanism with APP695 being the major APP isoform in neuronal, but not in non-neuronal cells (Sandbrink et al.,
1994). Although AICD derives from both amyloidogenic and non-amyloidogenic APP processing pathways and an $\alpha$-secretasedependent AICD generation was reported (Kume et al., 2004), several studies demonstrated the $\beta$-secretase mediated APP cleavage in endosomal compartments to be mainly responsible for the generation of transcriptionally active AICD species. Interestingly, Passer et al. (2000) already reported in the first study describing the existence of AICD, that overexpression of C99 results in larger amounts of AICD than overexpression of C83. Blocking the amyloidogenic APP processing by inhibition of endocytosis or inhibition/genetic deletion of BACE1 in fibroblasts, HEK293 cells, and primary neurons leads to a reduced translocation of AICD to nuclear AFT complexes, while inhibition of $\alpha$-secretase has no effect on AFT-complex generation (Goodger et al., 2009). This was 
confirmed by Belyaev et al. (2010) showing that inhibition of $\beta$ and $\gamma$-, but not $\alpha$-secretase in SH-SY5Y cells leads to abolished AICD-mediated upregulation of the AICD target gene NEP. The results of the studies mentioned above resulted in the model (illustrated in Figure 4), that AICD released by $\alpha / \gamma$-secretase cleavage at the plasma membrane is rapidly degraded in the cytosol by IDE and other proteases like Cathepsin B and truncated into C31 by caspase- 3 activity. In contrast, the AICD generated by amyloidogenic APP processing requiring the endocytotic pathway, can translocate to the nucleus due to a shorter distance resulting in less degradation of the peptide. There it forms a complex with MED12, Fe65, and Tip60 that is able to regulate gene expression (Beckett et al., 2012). Conversely, in a study by Flammang et al. AICD was shown to be predominantly derived from C99. In this study C84 or C100 was overexpressed in E. coli, purified and supplemented with mammalian $\gamma$-secretase containing membranes. Analyzing the generated amount of AICD revealed that under these conditions $\gamma$-secretase has a higher turnover of C99 compared to C83 resulting in a higher level of C99 derived AICD. Similar results were obtained by utilizing cell-derived, membrane-embedded C83/C99 from C83/C99 overexpressing mammalian cells (Flammang et al., 2012). This is consistent with the data generated by Passer et al., Goodger et al., and Belyaev et al., but argues against the cytoplasmatic AICD degradation to be responsible for the inefficiency of C83 derived AICD in forming AFT complexes and regulating transcription. The existence of a substrate inhibitory domain in C83 (ASID, A $\beta 17-23$ ) that inhibits $\gamma$-secretase activity is a possible explanation for the reduced affinity of $\gamma$-secretase toward C83 (Tian et al., 2010).

\section{Summary}

Amyloid precursor protein intracellular domain binds to Fe65 after its release from the membrane. This is followed by the translocation of the AICD/Fe65 complex to the nucleus, where the association with the histone acetyltransferase Tip60 and the formation of the transcriptionally active AFT complex takes place. Experimental evidence suggests that the AICD active in nuclear signaling is produced mainly from the APP695 isoform in a $\beta-/ \gamma$-secretase-dependent manner.

\section{IMPACT OF AICD IN THE REGULATION OF NEP}

Remarkably, in the case of an AICD-mediated upregulation of NEP, one APP cleavage product, AICD indirectly regulates the lifetime of another APP cleavage product, $\mathrm{A} \beta$, by upregulation of its degradation resulting in a regulatory cycle, in which $\gamma$-secretase is responsible for $\mathrm{A} \beta$ production and modulates its degradation at the same time. Importantly, it has been shown, that $A \beta$ and AICD generation by $\gamma$-secretase could be independently regulated (Chen et al., 2006; Wiley et al., 2007; He et al., 2010). In this cycle decreased AICD formation, for example by reduction of $\gamma$-secretase activity, genetic deletion of APP, or prevention of AICD transport to the nucleus, should result in reduced NEP expression leading to higher $\mathrm{A} \beta$ levels. This has been analyzed by several groups over the past years with inconsistent outcomes. An overview of the performed experiments and the generated results is given in Table 1.

Pardossi-Piquard et al. published, that $\gamma$-secretase inhibition and genetic deletion of PS1/PS2, nicastrin, Fe65, and the APP family members results in decreased NEP expression and activity in vitro and in vivo. In this studies NEP expression and activity were shown to be restored by transient expression of PS1, PS2, or the intracellular domains of APP, APLP1, and APLP2 (Pardossi-Piquard et al., 2005, 2006, 2007). In line with these findings, pharmacological inhibition of $\gamma$-secretase or RNAi-mediated APP knockdown in NB7 and SK-N-SH cells leads to significantly decreased NEP mRNA levels as reported by Xu et al. Interestingly, similar effects on NEP and other potential AICD target genes were observed by RNAi-mediated knockdown of MED12 identifying the protein as a transducer of AICD nuclear signaling for the first time (Xu et al., 2011). Furthermore, NEP gene promoters are transactivated by AICD in TSM1 neurons and fibroblasts shown by luciferase reporter assays (Pardossi-Piquard et al., 2005). A direct physical interaction of AICD with the NEP promoter was further confirmed by supergel shift assay analysis in HEK293 cells and chromatin immunoprecipitation (ChIP) (Pardossi-Piquard et al., 2005; Belyaev et al., 2009). AICD binds directly to the NEP promoter NB7 cells, which highly express NEP, and rat primary cortical neurons, but not in HUVEC (primary human umbilical vein endothelial) and SH-SY5Y cells, which only show a low NEP expression. In this study excess histone deacetylation was shown to be involved in NEP repression (Belyaev et al., 2009).

Other groups failed to reproduce the observed effects of AICD signaling on NEP expression, even by using broadly similar methodologies and partly the same cells for their experiments.

Hebert et al. (2006) found no consistent effect on NEP expression in several cell lines treated with $\gamma$-secretase-inhibitors and in fibroblasts bearing genetic deficiencies in the $\gamma$-secretase complex or the APP family members. There was also no alteration of NEP levels in tissues of APP/APLP1, PS1, or Aphla gene disrupted mouse embryos. Chen et al. also reported the lack of both PS1 and PS2 expression in mouse embryonic stem cells (BD8) not to alter NEP levels. In PS double KO fibroblasts NEP levels are decreased, but rescued $\gamma$-secretase activity by introduction of PS1 failed to rescue the effect on NEP levels. Cellular NEP levels are unaffected as well by inhibition of $\gamma$-secretase in fibroblasts, BD8, and HEK293 cells and by introduction of AICD, Tip60, and Fe65 in PS double KO BD8, BD8 wildtype, and HEK293 wildtype cells. Moreover, there was no change in NEP levels and activity in APP and APLP2 single KO mouse brain homogenates found (Chen and Selkoe, 2007). In a further study, gene-chip microarray analysis revealed no alterations of NEP expression in APP KO and PS1/PS2 double KO fibroblasts along with no alterations of NEP protein levels in APP/APLP2 single and double KO fibroblasts (Huysseune et al., 2009).

Several factors influencing the experimental outcomes, for example cell types, clonal heterogeneity, density and age of the used cells, transgenic mouse models (single vs. double $\mathrm{KO}$ ), and differences in incubation times/concentrations of the used inhibitors might explain the discussion about a function of AICD in gene regulation (Pardossi-Piquard et al., 2007; Bauer et al., 2011). Different cell lines may vary in the ratio of constitutive vs. regulated NEP expression. In consequence, detection of AICD regulated NEP expression is probably not possible in all cells. In line with this hypothesis Hong et al. (2012) failed to detect an influence of AICD on NEP in human prostate cells. As already mentioned, the distinct 


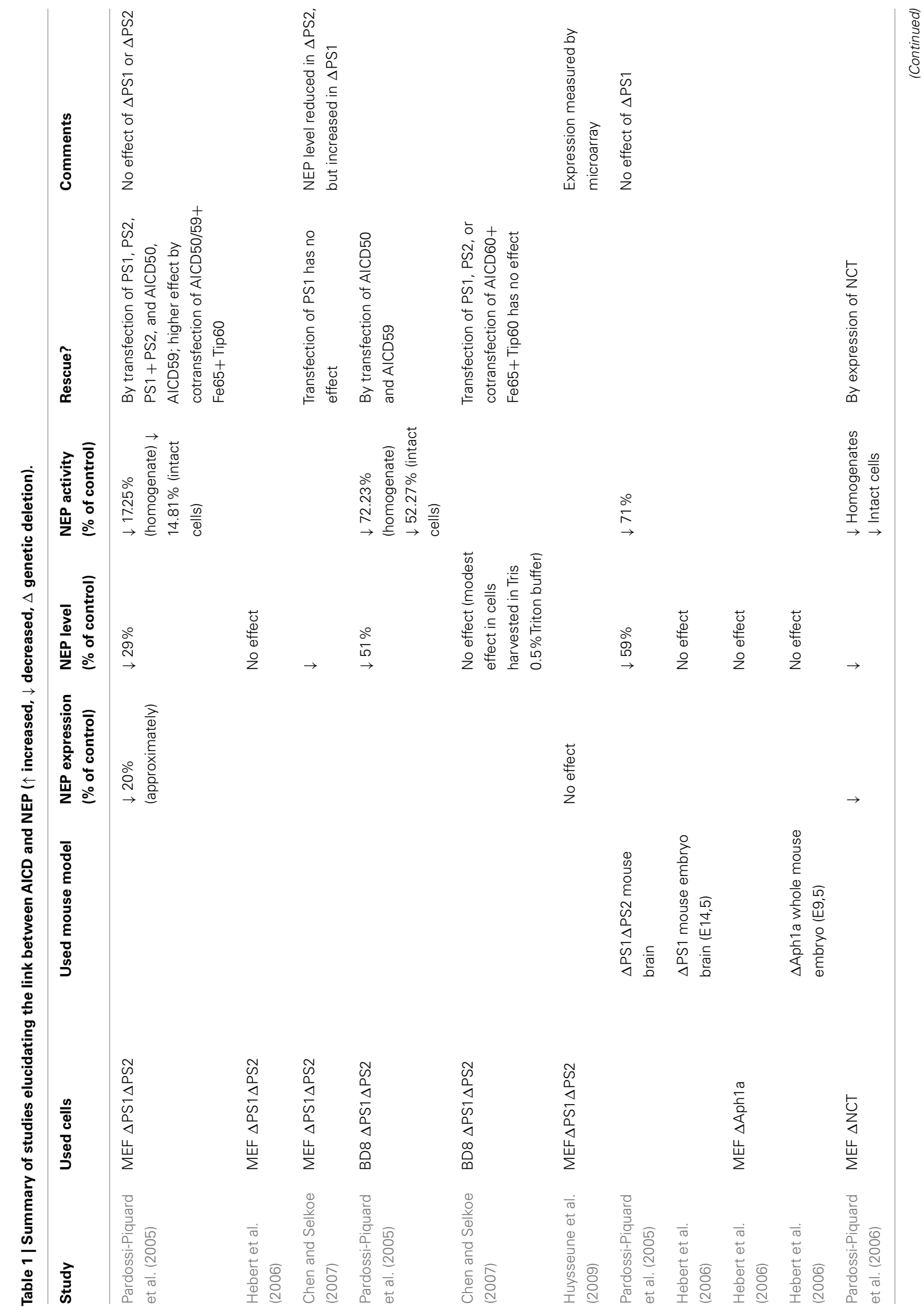




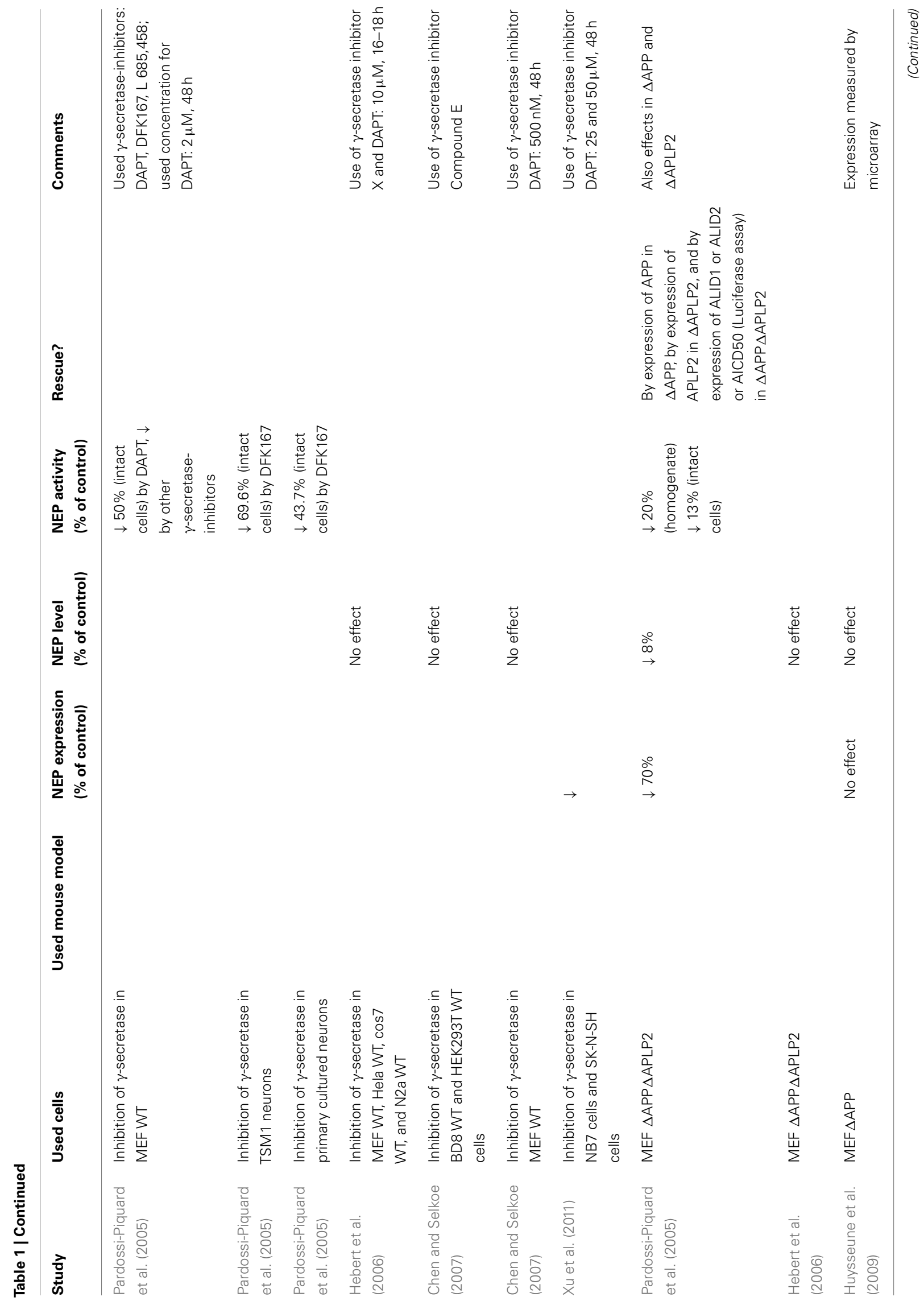




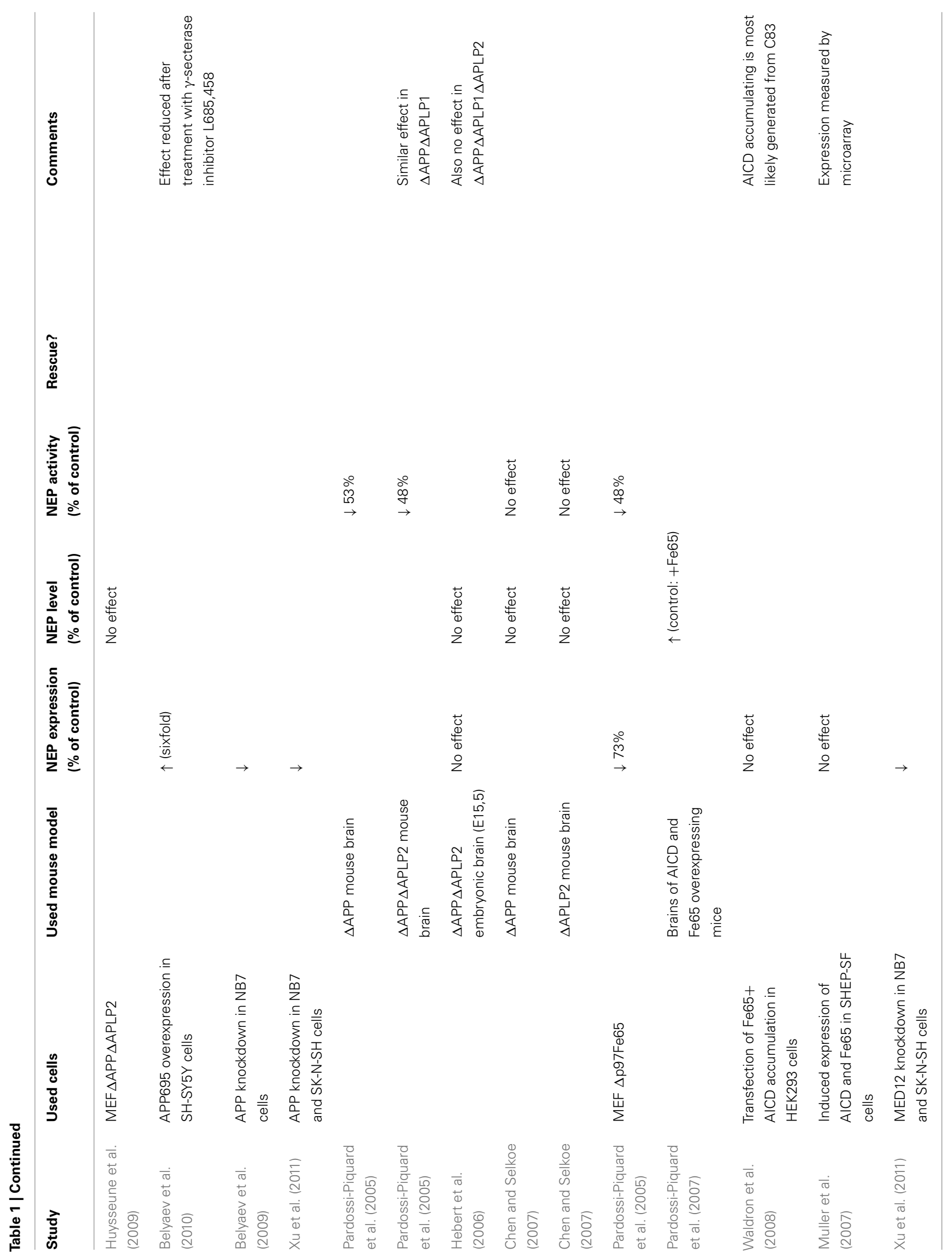


APP isoforms differ markedly in their ability to modulate NEP expression with transcriptionally active AICD being preferentially derived by $\beta$-secretase cleavage of APP695, the most prominent APP isoform in neuronal, but not in non-neuronal cells (Belyaev et al., 2010). This could additionally explain cell type specificity of the signaling pathway and the failure to observe AICD-mediated transcriptional activation in studies using non-neuronal cell lines.

Nevertheless, physical and functional interaction of AICD and regulatory elements of the NEP promoters has been clearly demonstrated (Pardossi-Piquard et al., 2005; Belyaev et al., 2009). Binding of AICD to these elements is followed by the displacement of HDAC1 (histone deacetylase 1) and hence the activation of transcription (Belyaev et al., 2009; Xu et al., 2011). The remodeling of chromatin by histone acetylation and deacetylation is an important mechanism of regulating gene expression in general. NEP expression in neuronal cells was shown to be repressed via competitive binding of HDACs to its promoter. Sodium valproate (valproic acid, VA), an anticonvulsant showing HDAC-inhibitory properties, is able to restore AICD promotor binding as well as $\mathrm{NEP}$ expression in vitro and in vivo and improves animal behavior and memory (Qing et al., 2008; Belyaev et al., 2009; Zhuravin et al., 2011; Nalivaeva et al., 2012), indicating the AICD dependent regulation of NEP to be an interesting therapeutical target.

Imatinib (Gleevec), a tyrosine kinase inhibitor used for the treatment of several cancers, shows another mode of action in the upregulation of NEP. Incubation of $\mathrm{H} 4$ cells with Imatinib results in reduced $A \beta$ levels accompanied by increased levels of both AICD and NEP (Eisele et al., 2007). A causative link between these effects was later given by the observation that the Imatinib-induced NEP elevation is totally abolished by genetic deletion of APP/APLP2 in fibroblasts. The authors suggest, that Imatinib treatment slows down AICD degradation resulting in increased NEP levels, higher $\mathrm{A} \beta$ degradation and hence to a reduction in $\mathrm{A} \beta$ levels (Bauer et al., 2011).

\section{Summary}

The impact of AICD on NEP expression has been demonstrated in several models by the use of different methods. In line a direct interaction between AICD and the NEP promoter region has been shown. In contrast, other studies exist reporting no AICD-mediated NEP regulation. NEP expression is upregulated by sodium valproate and Imatinib via inhibition of HDACs and of AICD degradation, respectively.

In conclusion, the regulation of NEP by AICD cannot be assumed in general, but rather for specific pools of AICD in certain tissues. It represents a potential therapeutic target for $\mathrm{AD}$. However, further studies elucidating potential side effects are necessary, especially by keeping in mind the high repertoire of NEP substrates and the potential role of AICD in the regulation of genes involved in a variety of cellular functions, as for example the initiation of apoptosis. A similar situation occurs by the approach of $\gamma$-secretase inhibition to treat AD because of various known targets of the $\gamma$-secretase.

\section{FURTHER POTENTIAL AICD TARGET GENES}

The controversial results obtained by AICD-mediated regulation of NEP is also reflected by other targets assumed to be regulated by AICD. Here we briefly summarize these studies to further evaluate the general transcriptional regulation mediated by AICD and therefore to get an impression why different results might have been obtained in literature.

Potential target genes of AICD nuclear signaling include retinoic acid-responsive genes (Gao and Pimplikar, 2001), KAI1/CD82 (Baek et al., 2002), glycogen synthase kinase-3 $\beta$ (GSK3 $\beta$ ) (Kim et al., 2003), APP, BACE1, Tip60 (Von Rotz et al., 2004), NEP (Pardossi-Piquard et al., 2005), p53 (Alves da Costa et al., 2006), Fibronectin1 (FN1), $\alpha 2$-actin, transgelin (SM22), tropomyosin 1 (TPM1), flavoprotein oxidoreductase MICAL2 (MICAL2), Ras-associated protein (RAB3B) (Muller et al., 2007), EGF receptor (EGFR) (Zhang et al., 2007), LRP (LRP1) (Liu et al., 2007), Cyclins B1 and D1 (Ahn et al., 2008), vesicular glutamate transporter (VGLUT2) (Schrenk-Siemens et al., 2008), C/EBP homologous protein (CHOP) (Takahashi et al., 2009), Aquaporin 1 (Huysseune et al., 2009), S100a9 (Ha et al., 2010), ApoJ/clusterin (Kogel et al., 2012), patched homolog 1 (Ptch1), transient receptor potential cation channel subfamily $\mathrm{C}$ member 5 (TRPC5) (Das et al., 2011), serine-palmitoyl transferase (SPT) subunit SPTLC2 (Grimm et al., 2011a), alkyl-dihydroxyacetonephosphate-synthase (AGPS) (Grimm et al., 2011b), GD3 synthase (GD3S) (Grimm et al., 2012), Stathmin1 (Muller et al., 2013), and PGC1 $\alpha$ (Robinson et al., 2013). A summary of these genes including the experimental procedures to investigate a potential impact of AICD on their expression are listed in Table 2.

The metastasis suppressor KAI1 was the first identified functionally significant AICD target gene. A direct interaction of the AFT complex with the KAI1 promoter region initiates the displacement of the N-CoR/TAB2/HDAC3 corepressor complex and leads to an increase of KAI1 mRNA and protein levels in the central nervous system of APP transgenic mice. In these mice the protein levels of APP, Fe65 and Tip60 are dramatically increased as well (Baek et al., 2002). The expression of glycogen synthase kinase-3 $\beta$ (GSK $3 \beta$ ), which is implicated in the hyperphosphorylation of tau in $\mathrm{AD}$, was also shown to be upregulated by AICD. Overexpression of AICD in PC12 cells and in rat primary cortical neurons induces the expression of GSK3 $\beta$ and its promoter activity. In this study the enhanced expression of GSK3 $\beta$ is followed by an increase in tau phosphorylation and a reduction of $\beta$-catenin levels, leading to apoptosis (Kim et al., 2003). The GSK3 $\beta$ mediated tau phosphorylation induced by AICD may provide a link between APP and tau, the two proteins that are responsible for the major pathologic hallmarks of AD. Von Rotz et al. (2004) confirmed the upregulation of KAI1, APP, BACE1, Tip60, and GSK3 $\beta$, but not Fe65, in HEK293 cells after inducible AICD overexpression, indicating a feed-forward mechanism, in which AICD upregulates the expression of its own precursor APP, the APP cleaving enzyme BACE1, involved in its generation, and Tip60, involved in its signaling pathway. The elevation of GSK3 $\beta$ activity by AICD was validated in vivo in AICD transgenic mice, where it results in enhanced phosphorylation of CPMP2 protein, a GSK3 $\beta$ substrate involved in axonal guidance (Ryan and Pimplikar, 2005). AICD is further linked to apoptosis by the observation that the proapoptotic tumor suppressor gene 53 is affected by AICD nuclear signaling. This may be an additional explanation for the AICD induced and Tip60 dependent cell death, which is abolished by p53 deficiency (Passer et al., 


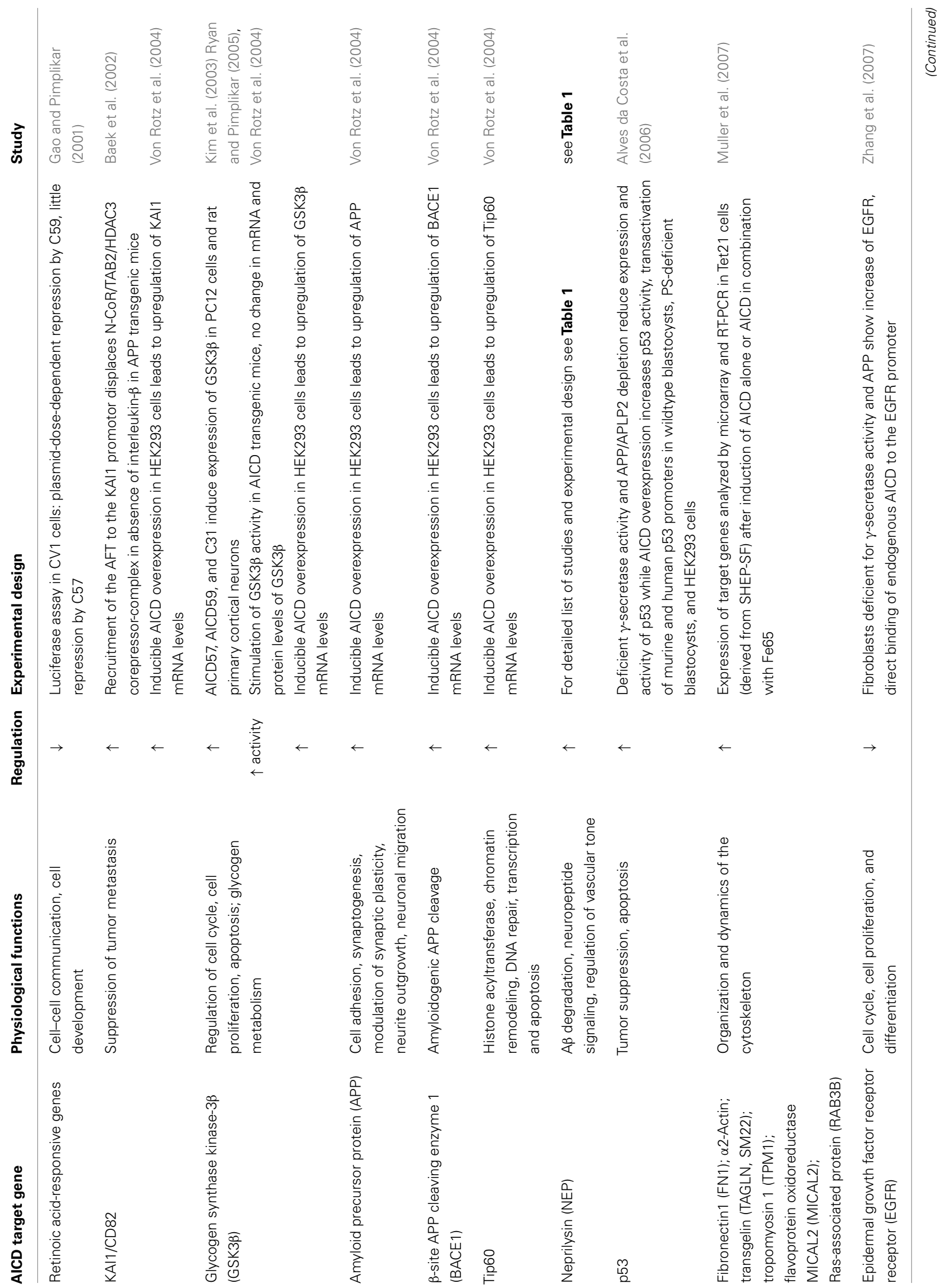




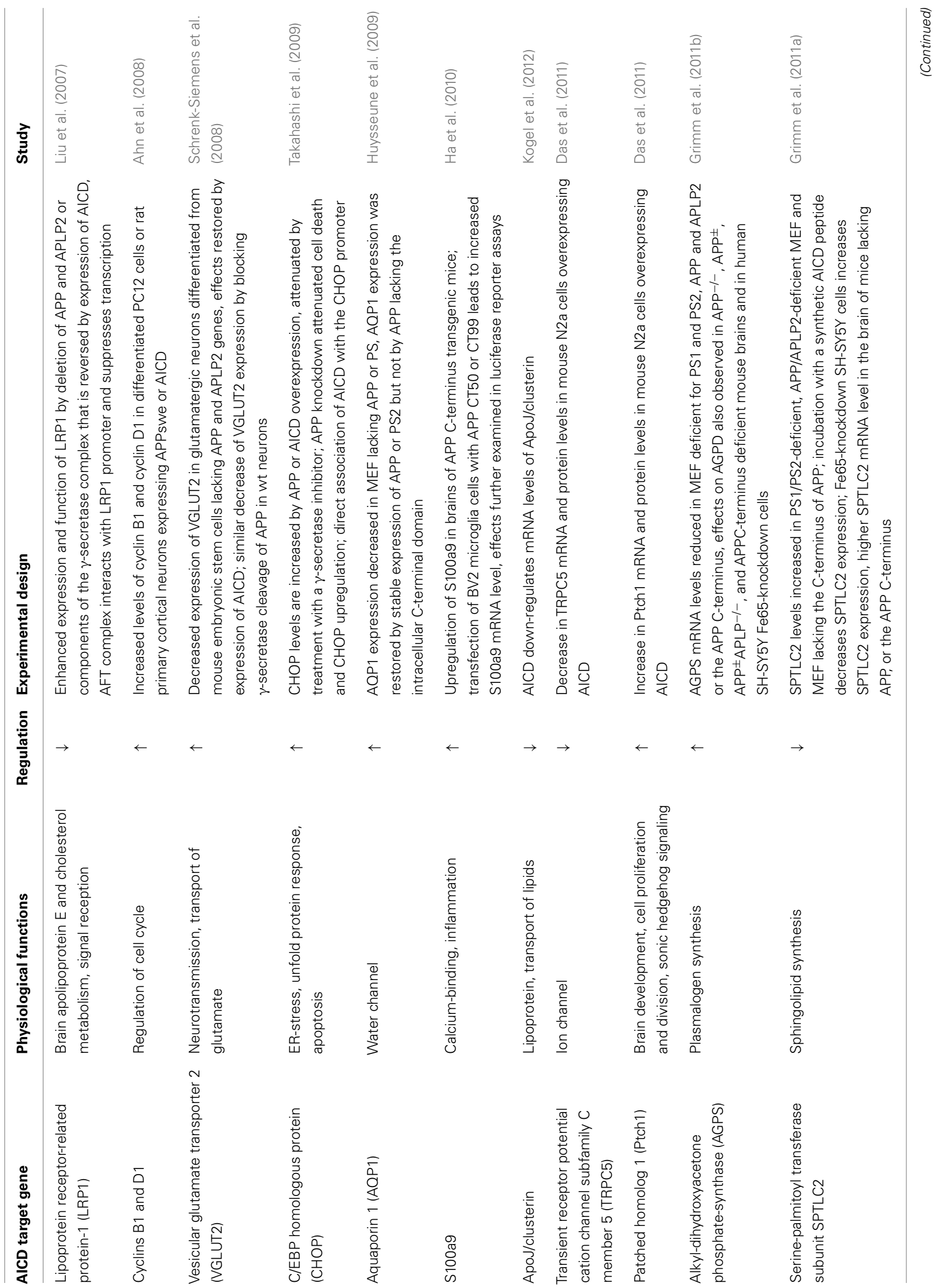




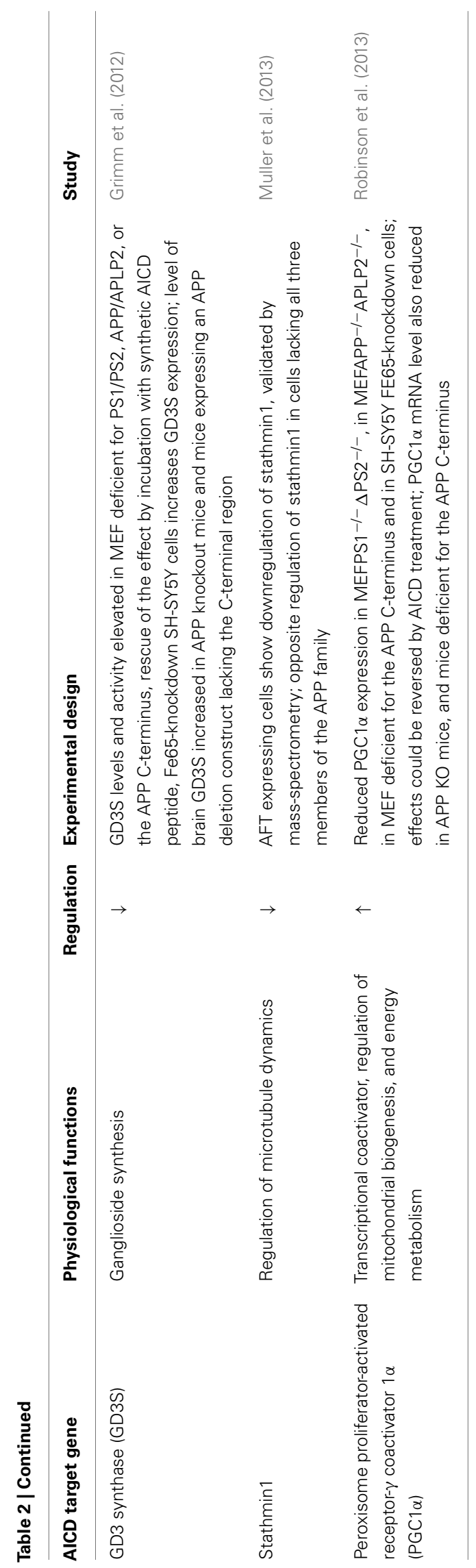

2000; Kinoshita et al., 2002; Ozaki et al., 2006). Genetic depletion of APP/APLP2 or PS and reduction of $\gamma$-secretase activity leads to decreased expression and activity of p53 and in line with this to a reduced activation of the $\mathrm{p} 53$ promoter. $\mathrm{p} 53$ expression is also diminished in vivo in the brains of PS- or APP-deficient mice. In contrast, enhanced $\mathrm{p} 53$ activity and $\mathrm{p} 53$ promoter transactivation was observed in AICD overexpressing blastocysts and HEK293 cells (Alves da Costa et al., 2006).

In contrast to the studies mentioned above, several authors failed to observe an impact of AICD on the regulation of the same target genes. Hébert et al. reported the protein levels of the potential AICD target genes APP and GSK3 $\beta$ not to be altered in cells treated with $\gamma$-secretase-inhibitors or in biological models genetically deficient for AICD generation. In line, analysis of the transactivation properties of AICD on the promoter regions of KAIl and APP only showed modest effects (Hebert et al., 2006). Transcriptome analysis of a human neuroblastoma cell line inducible for expression of AICD, Fe65 or both failed to identify differential expression of KAI1, GSK3 $\beta$, APP, and NEP. In this study real-time quantitative PCR confirmed that AICD or AICD/Fe65 expression is not associated with changes in the expression of either KAI1 or GSK3 $\beta$ (Muller et al., 2007). In a study by Waldron et al. increased AICD levels generated in the presence of $\mathrm{NH} 4 \mathrm{Cl}$, failed to stimulate the APP and KAI1 promoter regions in luciferase reporter assays. The lack of a transactivation potential of AICD on these genes is further demonstrated by the unchanged NEP, KAI1, BACE1, EGFR, Tip60, and p53 mRNA levels. It should be noted, that AICD accumulating under these conditions is derived from C83, indicating that it represents an AICD species that is discussed not to be transcriptionally active as mentioned above (Waldron et al., 2008).

\section{Summary}

Many conflicting data and models concerning the role of AICD in promoting the expression of several potential AICD target genes including NEP have emerged. This might be due to the short halflife of AICD, which per se complicates the finding of experimental conditions to elucidate the physiological role of AICD.

\section{ANALYSIS OF THE IMPACT OF AICD IN GENE REGULATION: EXPERIMENTAL CHALLENGES AND FURTHER APPROACHES}

Up to now the impact of AICD in gene regulation in general and in transcriptional regulation of NEP in particular is highly controversially discussed. As reviewed above several controversial findings have been published, which might be due the extraordinary experimental challenges of this topic. In this paragraph we will summarize these challenges and suitable methods to deal with these problems, briefly explaining the advantage and disadvantage of each method.

Addressing the role of AICD in gene regulation, the most prominent problem to deal with is the extremely short half-life of the peptide (Cupers et al., 2001) caused by proteolytic degradation by caspases, IDE or the proteasome (Gervais et al., 1999; Edbauer et al., 2002; Farris et al., 2003; Nunan et al., 2003). Especially the use of non-overexpressing systems or incubation of cells with physiological concentrations of AICD results in a false negative study outcome. However, it is possible to inhibit the AICD 
degrading processes with specific inhibitors, such as MG-132 and Epoxomicin for proteasome (Gersbacher et al., 2013) or Bacitracin for IDE resulting in an increased half-life of AICD. Using such inhibitors one has to be aware of the partially high cytotoxicity and that beside AICD the degradation of a huge amount of other proteins and peptides is also inhibited, making the conclusion from the obtained results more ambiguous.

Alternatively, higher concentrations of AICD can be used for incubation. However, it has to be taken into consideration that artificial assembly of AICD with adapter proteins might be the consequence, generating false positive results. The same problem occurs with APP overexpressing cell lines, where additionally missorting and protein accumulation might take place. Inducible promotors like used in TET-systems could help to overcome these challenges. Moreover, enhancing the AICD uptake by using lipofection reagents might be beneficial.

Beside the addition of the peptide and expressing AICD or its precursor constructs, reasonable results could be obtained by reducing the cellular amount of AICD. In principle APP KO, PS $\mathrm{KO}$, and BACE1 KO cells are available and often used for analysis. Utilizing these KOs, it has to be mentioned that beside AICD the generation of further APP cleavage products is inhibited as well, making it impossible to differentiate between the impact of AICD in comparison to other APP derived fragments.

Moreover, APP might accumulate due to inhibiting its catabolism and it has already been shown that APP itself is involved in transcriptional regulation as summarized in the next section. Beside the lack of other APP cleavage products and the accumulation of APP, $\gamma$-secretase as well as BACE1 have several other substrates, which are also affected by the KO, making it necessary to combine different approaches and to look for intersections of the obtained results. In addition to the false positive results obtained by affecting other proteins and mechanisms, APP KO models might also lead to false negative findings. As mentioned in Section "Proteolytic Processing of APP" not only APP but the whole APP family has AICD like domains (ALID1/2 in the case of APLP1 and APLP2), which can be released and are potentially transcriptionally active. It is assumed that ALID1 and ALID2 are at least partially able to compensate the lack of AICD. Therefore it should be considered to utilize combined APP/APLP1/APLP2-KO cells to investigate the effects of AICD. Furthermore it has to be pointed out that mostly, because of their ability to immortalize, mouse embryonic fibroblasts (MEFS) are used. It has been shown that AICD transcriptional regulation is at least in some cases tissue specific. Therefore results obtained from fibroblasts cannot be automatically transferred to other tissues like brain. To avoid these problems knock downs of the relevant proteins in neuronal cell lines like N2A (murine) and SH-SY5Y (human) cells or pharmacological inhibition of the secretases in these systems can be additionally used. However, it has to be balanced whether the toxicity of the inhibitors and the incomplete knock down of the proteins might affect the obtained findings. Moreover, beside the results found in cell culture experiments in vivo relevance has to be proofed. Using littermates for controls helps to reduce genetical heterogeneity. In living organisms it cannot be ruled out that compensating mechanisms make it more difficult to elucidate the role of a lacking peptide or protein, which might also result in reduced effect strength. On top of these problems many KO mouse models, like $\mathrm{PS} 1 / 2$ double $\mathrm{KO}$ or APP/APLPL2 double $\mathrm{KO}$ mice, are lethal in embryonic or early postnatal status (Wang et al., 2005a). For AICD transcriptional regulation of proteins involved in tissue differentiation are postulated (see Table 2). Especially the lethal phenotype of mice lacking APP and APLP2 in early stages aggravates the analysis of AICD function on gene transcription of these proteins.

In addition to the above mentioned KO systems, a truncated APP construct expressed in absence of the whole APP family is used in some studies (Huysseune et al., 2009; Grimm et al., 2011a,b). The truncated APP lacks the CTF and therefore AICD. By utilizing this system it is in principal possible to distinguish if an effect is caused by AICD or other APP cleavage products. However, the missing CTF also influences $A \beta$ generation making this differentiation less distinct. To avoid or circumvent this problem it might be helpful to test if the observed phenotype could be partially rescued by adding AICD peptide, combining the advantages and disadvantages of both systems. Additionally the analysis of the $\mathrm{KO}$ or knock down of AICD adaptor proteins like Fe65 might help to understand the underlying mechanism, especially in combination with other experimental approaches.

Finally, promoter analysis using, e.g., luciferase assays should be mentioned. Utilizing this approach it is possible to investigate if AICD is indeed able to affect the specific promotor regions of potential target genes. It has to be taken into consideration that these systems mainly use episomal vectors, making transport, or transport dependent processes to the nucleus unnecessary. This experimental approach is not suitable to distinguish between the transcriptional impact of C83 $(\alpha-\mathrm{CTF})$ and C99 $(\beta-\mathrm{CTF})$ derived AICD.

As no optimal experimental approach having no disadvantages is available, it has to be accepted that only the combination of different experimental methods and models is sufficient to unambiguously evaluate the role of AICD in gene regulation.

\section{Summary}

The combination of several genetic and/or pharmalogical approaches is necessary to elucidate the AICD-mediated regulation of potential AICD target genes. For genes found to be regulated by AICD in cell culture systems the in vivo relevance should be tested in animal models, and to rule out in general an effect of AICD several tissues have to be analyzed as the gene regulatory role of AICD seems to be tissue specific.

\section{GENE REGULATORY FUNCTIONS OF APP INDEPENDENT OF AICD}

Besides AICD, it has been reported that other APP cleavage products and even full length APP have an impact on gene regulation.

The secreted APP ectodomain possibly regulates downstream target genes via binding to one or several yet unknown receptor(s) activating intracellular pathways leading to altered gene expression. sAPP $\alpha$ was shown to increase the expression of several neuroprotective genes, among them transthyretin (TTR) and insulin-like growth factor-2 (IGF-2) in mouse organotypic hippocampal cultures and protects them from $A \beta$-induced tau phosphorylation and neuronal death (Stein et al., 2004). Recently, a study by Ryan et al. (2013) confirmed such a function of sAPP $\alpha$ in rat hippocampal organotypic slice cultures, where $\operatorname{sAPP} \alpha$ rapidly 
elicited a multi-level transcriptional response including the regulation of several transcription factors, microRNAs and the modulation of the chromatin environment. The kinase CDK5 and the chaperone ORP150 have been also reported to be regulated by sAPP $\alpha$. Treatment of neurons with sAPP $\alpha$ peptide leads to reduced expression and activity of CDK5, which is involved in the phosphorylation of tau and induces $A \beta$ generation (Cruz et al., 2006; Piedrahita et al., 2010). In contrast, the expression of the neuroprotective chaperone ORP150 (Kitao et al., 2001; Tamatani et al., 2001) is induced by sAPP $\alpha$ treatment. Importantly, these effects could not be observed in Sorl1-deficient neurons arguing for a role of SORLA as an essential sAPP $\alpha$ receptor (Hartl et al., 2013). In APP/APLP2-deficient mice the expression of TTR, involved in amyloid suppression (Schwarzman et al., 1994; Choi et al., 2007), and Klotho, related to various aging processes (Kuro-o et al., 1997; Kurosu et al., 2005) is downregulated. In contrast, an upregulation of TTR and Klotho mRNA levels was observed in sAPP $\beta$-knockin mice indicating a role of the APP $\beta$-cleaved ectodomain in the regulation of these genes ( $\mathrm{Li}$ et al., 2010).

Independent of $\operatorname{sAPP} \alpha, \operatorname{sAPP} \beta$, and AICD generation APP has been reported to regulate gene expression as well. Transcriptional downregulation of acetylcholinesterase (AchE) by full length APP was found in two neuronal cell lines (Hicks et al., 2013). Additionally, APP holoprotein was reported to regulate cholesterol metabolism at a transcriptional level. Pierrot et al. (2013) showed the expression of APP in rat cortical neurons to decrease both the mRNA levels of 3-hydroxy-3-methylglutarylcoenzym-A-reductase (HMGCR) and cholesterol 24-hydroxylase leading to a reduction in cholesterol turnover and to inhibition of neuronal activity. APP was further reported to downregulate the expression of the transcription factor EGR-1 at both mRNA and protein levels in vivo and in cultured neurons and in a $\gamma$-secretase-independent manner (Hendrickx et al., 2013). Additionally, intracellular $\mathrm{A} \beta$ peptide is discussed to act as transcription factor binding to $A \beta$ peptide interacting domain (A $\beta$ ID) sequences within the promoter regions of some genes. Ohyagi et al. (2005) showed intracellular A $\beta$ to directly activate the p53 promoter resulting in $\mathrm{p} 53$-dependent apoptosis. The transcription factors ASCL1 and OLIG2 are also regulated in cell culture by $A \beta$ (Uchida, JBC, 2007). Moreover, interactions between $A \beta$ and sequences within the APP and BACE1 promoters have been reported by the use of Chip assays on human neuroblastoma cells (Bailey et al., 2011) and by electrophoretic mobility shift assays (EMSA) indicating that $\mathrm{A} \beta$ peptide may regulate genes involved in its own production (Maloney and Lahiri, 2011). However, further studies concerning the role of APP and its cleavage products in gene regulation are necessary.

\section{Summary}

Impact in gene regulation is not only reported for AICD, but also for full length APP and its cleavage products $\operatorname{sAPP} \alpha, \operatorname{sAPP} \beta$, and $A \beta$.

\section{CONCLUDING REMARKS}

Summing it up, several lines of evidence underline the importance of NEP in A $\beta$ clearance. A reduced NEP activity has been associated with $A D$ and increased $A \beta$ levels. In return upregulation of NEP

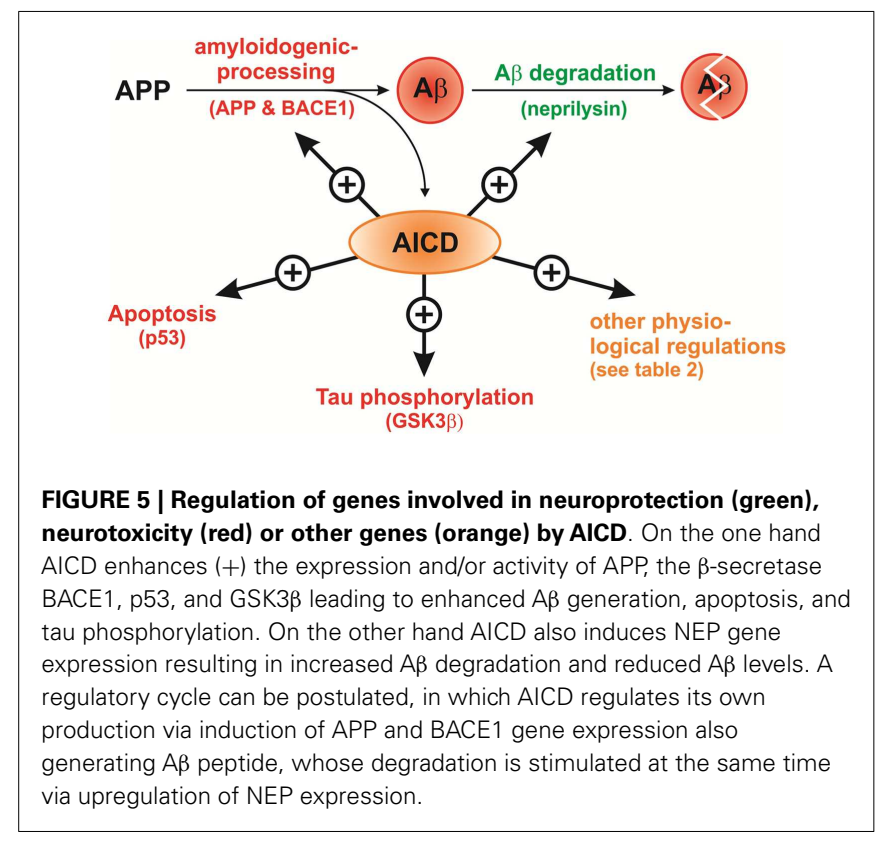

might be protective or beneficial for AD. However, the underlying mechanisms of NEP regulation are controversially discussed. One of the most favored models suggests that the amyloidogenic APP cleavage product, AICD, which has high similarities to Notch, is involved in the transcriptional regulation of NEP. Nevertheless additional studies will be necessary to further clarify the role of AICD in NEP regulation and to elucidate whether indeed NEP upregulation is suitable to prevent or treat AD. As AICD has been linked to the induction of genes both involved in neuroprotection and neurotoxicity, an upregulation of AICD can not be assumed as positive in general. On the one hand, AICD is discussed to upregulate the expression and/or activity of APP, BACE1, p53, and GSK3 $\beta$ leading to enhanced $A \beta$ generation, apoptosis and tau phosphorylation, all of these processes linked to neurotoxicity. On the other hand, AICD induces NEP expression leading to increased $A \beta$ degradation resulting in lowered $A \beta$ levels. Regarding the therapeutic potential of an AICD upregulation further studies are necessary to answer the question if the positive or negative consequences of an AICD upregulation predominate. Moreover, the site effects of an enhanced NEP level also need further investigation keeping in mind the numerous substrates of NEP including several neuropeptides.

A regulatory cycle can be postulated, in which AICD regulates its own production via induction of APP and BACE1 gene expression with the $A \beta$ peptide as secondary product, whose degradation is stimulated at the same time via upregulation of NEP gene expression (summarized in Figure 5). In a pathological situation like $\mathrm{AD}$ this cycle seems to be disturbed resulting in enhanced $\mathrm{A} \beta$ production along with reduced NEP levels leading to the severe accumulation of $A \beta$ in brain tissue.

\section{AUTHOR CONTRIBUTIONS}

Marcus O. W. Grimm, Janine Mett, Christoph P. Stahlmann, Viola J. Haupenthal, Valerie C. Zimmer, and Tobias Hartmann wrote the manuscript. 


\section{REFERENCES}

AD International. (2013). World Alzheimer Report. Illinois, USA: Alzheimer's Disease International Consortium.

Aguzzi, A., and Haass, C. (2003). Games played by rogue proteins in prion disorders and Alzheimer's disease. Science 302, 814-818. doi:10.1126/science.1087348

Ahn, K. W., Joo, Y., Choi, Y., Kim, M., Lee, S. H., Cha, S. H., et al. (2008). Swedish amyloid precursor protein mutation increases cell cycle-related proteins in vitro and in vivo. J. Neurosci. Res. 86, 2476-2487. doi:10.1002/jnr.21690

Akiyama, H., Kondo, H., Ikeda, K., Kato, M., and McGeer, P. L. (2001). Immunohistochemical localization of neprilysin in the human cerebral cortex: inverse association with vulnerability to amyloid beta-protein (Abeta) deposition. Brain Res. 902, 277-281. doi:10.1016/S0006-8993(01)02390-3

Alves da Costa, C., Sunyach, C., Pardossi-Piquard, R., Sevalle, J., Vincent, B., Boyer, N., et al. (2006). Presenilin-dependent gamma-secretase-mediated control of p53-associated cell death in Alzheimer's disease. J. Neurosci. 26, 6377-6385. doi:10.1523/JNEUROSCI.0651-06.2006

Ando, K., Iijima, K. I., Elliott, J. I., Kirino, Y., and Suzuki, T. (2001). Phosphorylationdependent regulation of the interaction of amyloid precursor protein with Fe65 affects the production of beta-amyloid. J. Biol. Chem. 276, 40353-40361. doi:10.1074/jbc.M104059200

Annweiler, C., Souberbielle, J. C., Schott, A. M., de Decker, L., Berrut, G., and Beauchet, O. (2011). Vitamin D in the elderly: 5 points to remember. Geriatr. Psychol. Neuropsychiatr. Vieil. 9, 259-267. doi:10.1684/pnv.2011.0288

Apelt, J., Ach, K., and Schliebs, R. (2003). Aging-related down-regulation of neprilysin, a putative beta-amyloid-degrading enzyme, in transgenic Tg2576 Alzheimer-like mouse brain is accompanied by an astroglial upregulation in the vicinity of beta-amyloid plaques. Neurosci. Lett. 339, 183-186. doi:10.1016/ S0304-3940(03)00030-2

Asai, M., Yagishita, S., Iwata, N., Saido, T. C., Ishiura, S., and Maruyama, K. (2011). An alternative metabolic pathway of amyloid precursor protein C-terminal fragments via cathepsin B in a human neuroglioma model. FASEB J. 25, 3720-3730. doi:10.1096/fj.11-182154

Aydin, D., Weyer, S. W., and Muller, U. C. (2012). Functions of the APP gene family in the nervous system: insights from mouse models. Exp. Brain Res. 217, 423-434. doi:10.1007/s00221-011-2861-2

Ayoub, S., and Melzig, M. F. (2006). Induction of neutral endopeptidase (NEP) activity of SK-N-SH cells by natural compounds from green tea. J. Pharm. Pharmacol. 58, 495-501. doi:10.1211/jpp.58.4.0009

Baek, S. H., Ohgi, K. A., Rose, D. W., Koo, E. H., Glass, C. K., and Rosenfeld, M. G. (2002). Exchange of N-CoR corepressor and Tip60 coactivator complexes links gene expression by NF-kappaB and beta-amyloid precursor protein. Cell 110, 55-67. doi:10.1016/S0092-8674(02)00809-7

Bailey, J. A., Maloney, B., Ge, Y. W., and Lahiri, D. K. (2011). Functional activity of the novel Alzheimer's amyloid beta-peptide interacting domain (AbetaID) in the APP and BACE1 promoter sequences and implications in activating apoptotic genes and in amyloidogenesis. Gene 488, 13-22. doi:10.1016/j.gene.2011. 06.017

Barbagallo, A. P., Wang, Z., Zheng, H., and D’Adamio, L. (2011). A single tyrosine residue in the amyloid precursor protein intracellular domain is essential for developmental function. J. Biol. Chem. 286, 8717-8721. doi:10.1074/jbc.C111. 219873

Barnes, K., Doherty, S., and Turner, A. J. (1995). Endopeptidase-24.11 is the integral membrane peptidase initiating degradation of somatostatin in the hippocampus. J. Neurochem. 64, 1826-1832. doi:10.1046/j.1471-4159.1995.64041826.x

Barnes, K., Turner, A. J., and Kenny, A. J. (1992). Membrane localization of endopeptidase-24.11 and peptidyl dipeptidase A (angiotensin converting enzyme) in the pig brain: a study using subcellular fractionation and electron microscopic immunocytochemistry. J. Neurochem. 58, 2088-2096. doi:10.1111/ j.1471-4159.1992.tb10950.x

Barron, A. M., and Pike, C. J. (2012). Sex hormones, aging, and Alzheimer's disease. Front. Biosci. (Elite Ed.) 4:976-997. doi:10.2741/434

Bauer, C., Pardossi-Piquard, R., Dunys, J., Roy, M., and Checler, F. (2011). gammaSecretase-mediated regulation of neprilysin: influence of cell density and aging and modulation by imatinib. J. Alzheimers Dis. 27, 511-520. doi:10.3233/JAD2011-110746

Baulac, S., LaVoie, M. J., Kimberly, W. T., Strahle, J., Wolfe, M. S., Selkoe, D. J., et al. (2003). Functional gamma-secretase complex assembly in Golgi/transGolgi network: interactions among presenilin, nicastrin, Aph1, Pen-2, and gamma-secretase substrates. Neurobiol. Dis. 14, 194-204. doi:10.1016/S09699961(03)00123-2

Beckett, C., Nalivaeva, N. N., Belyaev, N. D., and Turner, A. J. (2012). Nuclear signalling by membrane protein intracellular domains: the AICD enigma. Cell. Signal. 24, 402-409. doi:10.1016/j.cellsig.2011.10.007

Belyaev, N. D., Kellett, K. A., Beckett, C., Makova, N. Z., Revett, T. J., Nalivaeva, N. N., et al. (2010). The transcriptionally active amyloid precursor protein (APP) intracellular domain is preferentially produced from the 695 isoform of APP in a $\{$ beta $\}$-secretase-dependent pathway. J. Biol. Chem. 285, 41443-41454. doi:10.1074/jbc.M110.141390

Belyaev, N. D., Nalivaeva, N. N., Makova, N. Z., and Turner, A. J. (2009). Neprilysin gene expression requires binding of the amyloid precursor protein intracellular domain to its promoter: implications for Alzheimer disease. EMBO Rep. 10, 94-100. doi:10.1038/embor.2008.222

Betts, V., Leissring, M. A., Dolios, G., Wang, R., Selkoe, D. J., and Walsh, D. M. (2008). Aggregation and catabolism of disease-associated intra-Abeta mutations: reduced proteolysis of AbetaA21G by neprilysin. Neurobiol. Dis. 31, 442-450. doi:10.1016/j.nbd.2008.06.001

Binder, L. I., Guillozet-Bongaarts, A. L., Garcia-Sierra, F., and Berry, R. W. (2005). Tau, tangles, and Alzheimer's disease. Biochim. Biophys. Acta 1739, 216-223. doi:10.1016/j.bbadis.2004.08.014

Borggrefe, T., and Oswald, F. (2009). The Notch signaling pathway: transcriptional regulation at Notch target genes. Cell. Mol. Life Sci. 66, 1631-1646. doi:10.1007/s00018-009-8668-7

Borquez, D. A., and Gonzalez-Billault, C. (2012). The amyloid precursor protein intracellular domain-fe65 multiprotein complexes: a challenge to the amyloid hypothesis for Alzheimer's disease? Int. J. Alzheimers Dis. 2012, 353145 doi:10.1155/2012/353145

Briones, T. L., and Darwish, H. (2012). Vitamin D mitigates age-related cognitive decline through the modulation of pro-inflammatory state and decrease in amyloid burden. J. Neuroinflammation 9, 244. doi:10.1186/1742-2094-9-244

Brown, G., Greaves, M. F., Lister, T. A., Rapson, N., and Papamichael, M. (1974). Expression of human $\mathrm{T}$ and B lymphocyte cell-surface markers on leukaemic cells. Lancet 2, 753-755. doi:10.1016/S0140-6736(74)90945-3

Brown, G., Hogg, N., and Greaves, M. (1975). Candidate leukaemia-specific antigen in man. Nature 258, 454-456. doi:10.1038/258454a0

Bugiani, O., Giaccone, G., Rossi, G., Mangieri, M., Capobianco, R., Morbin, M., et al. (2010). Hereditary cerebral hemorrhage with amyloidosis associated with the E693K mutation of APP. Arch. Neurol. 67, 987-995. doi:10.1001/archneurol. 2010.178

Caccamo, A., Oddo, S., Sugarman, M. C., Akbari, Y., and LaFerla, F. M. (2005). Age- and region-dependent alterations in Abeta-degrading enzymes: implications for Abeta-induced disorders. Neurobiol. Aging 26, 645-654. doi:10.1016/j. neurobiolaging.2004.06.013

Cao, X., and Sudhof, T. C. (2001). A transcriptionally [correction of transcriptively] active complex of APP with Fe65 and histone acetyltransferase Tip60. Science 293, 115-120. doi:10.1126/science. 1058783

Cao, X., and Sudhof, T. C. (2004). Dissection of amyloid-beta precursor proteindependent transcriptional transactivation. J. Biol. Chem. 279, 24601-24611. doi:10.1074/jbc.M402248200

Carey, R. M., Balcz, B. A., Lopez-Coviella, I., and Slack, B. E. (2005). Inhibition of dynamin-dependent endocytosis increases shedding of the amyloid precursor protein ectodomain and reduces generation of amyloid beta protein. BMC Cell Biol. 6:30. doi:10.1186/1471-2121-6-30

Carpentier, M., Robitaille, Y., DesGroseillers, L., Boileau, G., and Marcinkiewicz, M. (2002). Declining expression of neprilysin in Alzheimer disease vasculature: possible involvement in cerebral amyloid angiopathy. J. Neuropathol. Exp. Neurol. 61, 849-856.

Carson, J. A., and Turner, A. J. (2002). Beta-amyloid catabolism: roles for neprilysin (NEP) and other metallopeptidases? J. Neurochem. 81, 1-8. doi:10.1046/j.14714159.2002.00855.X

Carter, T. L., Pedrini, S., Ghiso, J., Ehrlich, M. E., and Gandy, S. (2006). Brain neprilysin activity and susceptibility to transgene-induced Alzheimer amyloidosis. Neurosci. Lett. 392, 235-239. doi:10.1016/j.neulet.2005.09.022

Chang, K. A., Kim, H. S., Ha, T. Y., Ha, J. W., Shin, K. Y., Jeong, Y. H., et al. (2006). Phosphorylation of amyloid precursor protein (APP) at Thr668 regulates the nuclear translocation of the APP intracellular domain and induces neurodegeneration. Mol. Cell. Biol. 26, 4327-4338. doi:10.1128/MCB.02393-05 
Chavez-Gutierrez, L., Bammens, L., Benilova, I., Vandersteen, A., Benurwar, M., Borgers, M., et al. (2012). The mechanism of gamma-Secretase dysfunction in familial Alzheimer disease. EMBO J. 31, 2261-2274. doi:10.1038/emboj.2012.79

Chen, A. C., and Selkoe, D. J. (2007). Response to: Pardossi-Piquard et al., "presenilin-dependent transcriptional control of the Abeta-degrading enzyme neprilysin by intracellular domains of betaAPP and APLP.” Neuron 46, 541-554. Neuron 53, 479-483. doi:10.1016/j.neuron.2007.01.023

Chen, F., Hasegawa, H., Schmitt-Ulms, G., Kawarai, T., Bohm, C., Katayama, T., et al. (2006). TMP21 is a presenilin complex component that modulates gamma-secretase but not epsilon-secretase activity. Nature 440, 1208-1212. doi:10.1038/nature04667

Chen, W. J., Goldstein, J. L., and Brown, M. S. (1990). NPXY, a sequence often found in cytoplasmic tails, is required for coated pit-mediated internalization of the low density lipoprotein receptor. J. Biol. Chem. 265, 3116-3123.

Choi, S. H., Leight, S. N., Lee, V. M., Li, T., Wong, P. C., Johnson, J. A., et al. (2007). Accelerated Abeta deposition in APPswe/PS1deltaE9 mice with hemizygous deletions of TTR (transthyretin). J. Neurosci. 27, 7006-7010. doi:10.1523/ JNEUROSCI.1919-07.2007

Cirrito, J. R., May, P. C., O’Dell, M. A., Taylor, J. W., Parsadanian, M., Cramer, J. W., et al. (2003). In vivo assessment of brain interstitial fluid with microdialysis reveals plaque-associated changes in amyloid-beta metabolism and half-life. J. Neurosci. 23, 8844-8853.

Cleary, J. P., Walsh, D. M., Hofmeister, J. J., Shankar, G. M., Kuskowski, M. A., Selkoe, D. J., et al. (2005). Natural oligomers of the amyloid-beta protein specifically disrupt cognitive function. Nat. Neurosci. 8, 79-84. doi:10.1038/nn1372

Crouch, P. J., Tew, D. J., Du, T., Nguyen, D. N., Caragounis, A., Filiz, G., et al. (2009). Restored degradation of the Alzheimer's amyloid-beta peptide by targeting amyloid formation. J. Neurochem. 108, 1198-1207. doi:10.1111/j.1471-4159.2009. 05870.x

Cruz, J. C., Kim, D., Moy, L. Y., Dobbin, M. M., Sun, X., Bronson, R. T., et al. (2006). p25/cyclin-dependent kinase 5 induces production and intraneuronal accumulation of amyloid beta in vivo. J. Neurosci. 26, 10536-10541. doi:10.1523/JNEUROSCI.3133-06.2006

Cupers, P., Orlans, I., Craessaerts, K., Annaert, W., and De Strooper, B. (2001). The amyloid precursor protein (APP)-cytoplasmic fragment generated by gammasecretase is rapidly degraded but distributes partially in a nuclear fraction of neurones in culture. J. Neurochem. 78, 1168-1178. doi:10.1046/j.1471-4159.2001. 00516.x

D’Adamio, L., Shipp, M. A., Masteller, E. L., and Reinherz, E. L. (1989). Organization of the gene encoding common acute lymphoblastic leukemia antigen (neutral endopeptidase 24.11): multiple miniexons and separate $5^{\prime}$ untranslated regions. Proc. Natl. Acad. Sci. U.S.A. 86, 7103-7107. doi:10.1073/pnas.86.18.7103

Dahlgren, K. N., Manelli, A. M., Stine, W. B. Jr., Baker, L. K., Krafft, G. A., and LaDu, M. J. (2002). Oligomeric and fibrillar species of amyloid-beta peptides differentially affect neuronal viability. J. Biol. Chem. 277, 32046-32053. doi:10.1074/jbc.M201750200

Das, S., Raychaudhuri, M., Sen, U., and Mukhopadhyay, D. (2011). Functional implications of the conformational switch in AICD peptide upon binding to Grb2SH2 domain. J. Mol. Biol. 414, 217-230. doi:10.1016/j.jmb.2011.09.046

Davies, P., Katzman, R., and Terry, R. D. (1980). Reduced somatostatin-like immunoreactivity in cerebral cortex from cases of Alzheimer disease and Alzheimer senile dementia. Nature 288, 279-280. doi:10.1038/288279a0

De Strooper, B., Annaert, W., Cupers, P., Saftig, P., Craessaerts, K., Mumm, J. S., et al. (1999). A presenilin-1-dependent gamma-secretase-like protease mediates release of Notch intracellular domain. Nature 398, 518-522. doi:10.1038/19083

Deane, R., Du Yan, S., Submamaryan, R. K., LaRue, B., Jovanovic, S., Hogg, E., et al. (2003). RAGE mediates amyloid-beta peptide transport across the bloodbrain barrier and accumulation in brain. Nat. Med. 9, 907-913. doi:10.1038/ $\mathrm{nm} 890$

Duering, M., Grimm, M. O., Grimm, H. S., Schroder, J., and Hartmann, T. (2005). Mean age of onset in familial Alzheimer's disease is determined by amyloid beta 42. Neurobiol. Aging 26, 785-788. doi:10.1016/j.neurobiolaging.2004.08.002

Dyrks, T., Weidemann, A., Multhaup, G., Salbaum, J. M., Lemaire, H. G., Kang, J., et al. (1988). Identification, transmembrane orientation and biogenesis of the amyloid A4 precursor of Alzheimer's disease. EMBO J. 7, 949-957.

Eckman, E. A., Reed, D. K., and Eckman, C. B. (2001). Degradation of the Alzheimer's amyloid beta peptide by endothelin-converting enzyme. J. Biol. Chem. 276, 24540-24548. doi:10.1074/jbc.M007579200
Edbauer, D., Willem, M., Lammich, S., Steiner, H., and Haass, C. (2002). Insulindegrading enzyme rapidly removes the beta-amyloid precursor protein intracellular domain (AICD). J. Biol. Chem. 277, 13389-13393. doi:10.1074/jbc. M111571200

Edbauer, D., Winkler, E., Regula, J. T., Pesold, B., Steiner, H., and Haass, C. (2003). Reconstitution of gamma-secretase activity. Nat. Cell Biol. 5, 486-488. doi:10.1038/ncb960

Eggert, S., Paliga, K., Soba, P., Evin, G., Masters, C. L., Weidemann, A., et al. (2004). The proteolytic processing of the amyloid precursor protein gene family members APLP-1 and APLP-2 involves alpha-, beta-, gamma-, and epsilon-like cleavages: modulation of APLP-1 processing by n-glycosylation. J. Biol. Chem. 279, 18146-18156. doi:10.1074/jbc.M311601200

Ehehalt, R., Keller, P., Haass, C., Thiele, C., and Simons, K. (2003). Amyloidogenic processing of the Alzheimer beta-amyloid precursor protein depends on lipid rafts. J. Cell Biol. 160, 113-123. doi:10.1083/jcb.200207113

Eisele, Y. S., Baumann, M., Klebl, B., Nordhammer, C., Jucker, M., and Kilger, E. (2007). Gleevec increases levels of the amyloid precursor protein intracellular domain and of the amyloid-beta degrading enzyme neprilysin. Mol. Biol. Cell 18, 3591-3600. doi:10.1091/mbc.E07-01-0035

El-Amouri, S. S., Zhu, H., Yu, J., Marr, R., Verma, I. M., and Kindy, M. S. (2008). Neprilysin: an enzyme candidate to slow the progression of Alzheimer's disease. Am. J. Pathol. 172, 1342-1354. doi:10.2353/ajpath.2008.070620

Erdos, E. G., and Skidgel, R. A. (1988). Human neutral endopeptidase 24.11 (NEP, enkephalinase); function, distribution and release. Adv. Exp. Med. Biol. 240, 13-21. doi:10.1007/978-1-4613-1057-0_2

Farris, W., Mansourian, S., Chang, Y., Lindsley, L., Eckman, E. A., Frosch, M. P., et al. (2003). Insulin-degrading enzyme regulates the levels of insulin, amyloid betaprotein, and the beta-amyloid precursor protein intracellular domain in vivo. Proc. Natl. Acad. Sci. U.S.A. 100, 4162-4167. doi:10.1073/pnas.0230450100

Fisk, L., Nalivaeva, N. N., Boyle, J. P., Peers, C. S., and Turner, A. J. (2007). Effects of hypoxia and oxidative stress on expression of neprilysin in human neuroblastoma cells and rat cortical neurones and astrocytes. Neurochem. Res. 32, 1741-1748. doi:10.1007/s11064-007-9349-2

Flammang, B., Pardossi-Piquard, R., Sevalle, J., Debayle, D., Dabert-Gay, A. S., Thevenet, A., et al. (2012). Evidence that the amyloid-beta protein precursor intracellular domain, AICD, derives from beta-secretase-generated C-terminal fragment. J. Alzheimers Dis. 30, 145-153. doi:10.3233/JAD-2012-112186

Fukami, S., Watanabe, K., Iwata, N., Haraoka, J., Lu, B., Gerard, N. P., et al. (2002). Abeta-degrading endopeptidase, neprilysin, in mouse brain: synaptic and axonal localization inversely correlating with Abeta pathology. Neurosci. Res. 43, 39-56. doi:10.1016/S0168-0102(02)00015-9

Funamoto, S., Morishima-Kawashima, M., Tanimura, Y., Hirotani, N., Saido, T. C., and Ihara, Y. (2004). Truncated carboxyl-terminal fragments of beta-amyloid precursor protein are processed to amyloid beta-proteins 40 and 42 . Biochemistry 43, 13532-13540. doi:10.1021/bi049399k

Gahete, M. D., Rubio, A., Duran-Prado, M., Avila, J., Luque, R. M., and Castano, J. P. (2010). Expression of Somatostatin, cortistatin, and their receptors, as well as dopamine receptors, but not of neprilysin, are reduced in the temporal lobe of Alzheimer's disease patients. J. Alzheimers Dis. 20, 465-475. doi:10.3233/JAD-2010-1385

Gao, Y., and Pimplikar, S. W. (2001). The gamma-secretase-cleaved C-terminal fragment of amyloid precursor protein mediates signaling to the nucleus. Proc. Natl. Acad. Sci. U.S.A. 98, 14979-14984. doi:10.1073/pnas.261463298

Gersbacher, M. T., Goodger, Z. V., Trutzel, A., Bundschuh, D., Nitsch, R. M., and Konietzko, U. (2013). Turnover of amyloid precursor protein family members determines their nuclear signaling capability. PLoS ONE 8:e69363. doi:10.1371/journal.pone.0069363

Gervais, F. G., Xu, D., Robertson, G. S., Vaillancourt, J. P., Zhu, Y., Huang, J., et al. (1999). Involvement of caspases in proteolytic cleavage of Alzheimer's amyloidbeta precursor protein and amyloidogenic Abeta peptide formation. Cell 97, 395-406. doi:10.1016/S0092-8674(00)80748-5

Glenner, G. G., and Wong, C. W. (1984). Alzheimer's disease: initial report of the purification and characterization of a novel cerebrovascular amyloid protein. Biochem. Biophys. Res. Commun. 120, 885-890. doi:10.1016/S0006-291X(84) 80190-4

Gohring, B., Holzhausen, H. J., Meye, A., Heynemann, H., Rebmann, U., Langner, J., et al. (1998). Endopeptidase 24.11/CD10 is down-regulated in renal cell cancer. Int. J. Mol. Med. 2, 409-414. 
Goodger, Z. V., Rajendran, L., Trutzel, A., Kohli, B. M., Nitsch, R. M., and Konietzko, U. (2009). Nuclear signaling by the APP intracellular domain occurs predominantly through the amyloidogenic processing pathway. J. Cell. Sci. 122(Pt 20), 3703-3714. doi:10.1242/jcs.048090

Grbovic, O. M., Mathews, P. M., Jiang, Y., Schmidt, S. D., Dinakar, R., SummersTerio, N. B., et al. (2003). Rab5-stimulated up-regulation of the endocytic pathway increases intracellular beta-cleaved amyloid precursor protein carboxylterminal fragment levels and Abeta production. J. Biol. Chem. 278, 31261-31268. doi:10.1074/jbc.M304122200

Grimm, M. O., Grosgen, S., Rothhaar, T. L., Burg, V. K., Hundsdorfer, B., Haupenthal, V. J., et al. (2011a). Intracellular APP domain regulates serine-palmitoyl-CoA transferase expression and is affected in Alzheimer's disease. Int. J. Alzheimers Dis. 2011, 695413. doi:10.4061/2011/695413

Grimm, M. O., Kuchenbecker, J., Rothhaar, T. L., Grosgen, S., Hundsdorfer, B., Burg, V. K., et al. (2011b). Plasmalogen synthesis is regulated via alkyldihydroxyacetonephosphate-synthase by amyloid precursor protein processing and is affected in Alzheimer's disease. J. Neurochem. 116, 916-925. doi:10.1111/ j.1471-4159.2010.07070.x

Grimm, M. O., Lehmann, J., Mett, J., Zimmer, V. C., Grösgen, S., Stahlmann, C. P., et al. (2013). Impact of vitamin D on amyloid precursor protein processing and amyloid-beta peptide degradation in Alzheimer's disease. Neurodegener. Dis. doi:10.1159/000355462

Grimm, M. O., Tomic, I., and Hartmann, T. (2002). Potential external source of Abeta in biological samples. Nat. Cell Biol. 4, E164-E165. doi:10.1038/ncb0702-e164b author reply E5-6,

Grimm, M. O., Zinser, E. G., Grosgen, S., Hundsdorfer, B., Rothhaar, T. L., Burg, V. K., et al. (2012). Amyloid precursor protein (APP) mediated regulation of ganglioside homeostasis linking Alzheimer's disease pathology with ganglioside metabolism. PLoS ONE 7:e34095. doi:10.1371/journal.pone.0034095

Grundke-Iqbal, I., Iqbal, K., Quinlan, M., Tung, Y. C., Zaidi, M. S., and Wisniewski, H. M. (1986). Microtubule-associated protein tau. A component of Alzheimer paired helical filaments. J. Biol. Chem. 261, 6084-6089.

Gu, Y., Misonou, H., Sato, T., Dohmae, N., Takio, K., and Ihara, Y. (2001). Distinct intramembrane cleavage of the beta-amyloid precursor protein family resembling gamma-secretase-like cleavage of Notch. J. Biol. Chem. 276, 35235-35238. doi:10.1074/jbc.C100357200

Guenette, S., Chang, Y., Hiesberger, T., Richardson, J. A., Eckman, C. B., Eckman, E. A., et al. (2006). Essential roles for the FE65 amyloid precursor proteininteracting proteins in brain development. EMBO J. 25, 420-431. doi:10.1038/ sj.emboj.7600926

Ha, T. Y., Chang, K. A., Kim, J., Kim, H. S., Kim, S., Chong, Y. H., et al. (2010). S100a9 knockdown decreases the memory impairment and the neuropathology in Tg2576 mice, AD animal model. PLoS ONE 5:e8840. doi:10.1371/journal. pone. 0008840

Haass, C., Schlossmacher, M. G., Hung, A. Y., Vigo-Pelfrey, C., Mellon, A., Ostaszewski, B. L., et al. (1992). Amyloid beta-peptide is produced by cultured cells during normal metabolism. Nature 359, 322-325. doi:10.1038/359322a0

Haass, C., and Selkoe, D. J. (2007). Soluble protein oligomers in neurodegeneration: lessons from the Alzheimer's amyloid beta-peptide. Nat. Rev. Mol. Cell Biol. 8, 101-112. doi:10.1038/nrm2101

Hama, E., and Saido, T. C. (2005). Etiology of sporadic Alzheimer's disease: somatostatin, neprilysin, and amyloid beta peptide. Med. Hypotheses 65, 498-500. doi:10.1016/j.mehy.2005.02.045

Hama, E., Shirotani, K., Iwata, N., and Saido, T. C. (2004). Effects of neprilysin chimeric proteins targeted to subcellular compartments on amyloid beta peptide clearance in primary neurons. J. Biol. Chem. 279, 30259-30264. doi:10.1074/ jbc.M401891200

Hama, E., Shirotani, K., Masumoto, H., Sekine-Aizawa, Y., Aizawa, H., and Saido, T. C. (2001). Clearance of extracellular and cell-associated amyloid beta peptide through viral expression of neprilysin in primary neurons. J. Biochem. 130, 721-726. doi:10.1093/oxfordjournals.jbchem.a003040

Hardy, J. (1997). Amyloid, the presenilins and Alzheimer's disease. Trends Neurosci. 20, 154-159. doi:10.1016/S0166-2236(96)01030-2

Hardy, J., and Selkoe, D. J. (2002). The amyloid hypothesis of Alzheimer's disease: progress and problems on the road to therapeutics. Science 297, 353-356. doi:10.1126/science.1072994

Hardy, J. A., and Higgins, G. A. (1992). Alzheimer's disease: the amyloid cascade hypothesis. Science 256, 184-185. doi:10.1126/science.1566067
Hartl, D., Klatt, S., Roch, M., Konthur, Z., Klose, J., Willnow, T. E., et al. (2013). Soluble alpha-APP (sAPPalpha) regulates CDK5 expression and activity in neurons. PLoS ONE 8:e65920. doi:10.1371/journal.pone.0065920

Hashimoto, Y., Niikura, T., Tajima, H., Yasukawa, T., Sudo, H., Ito, Y., et al. (2001). A rescue factor abolishing neuronal cell death by a wide spectrum of familial Alzheimer's disease genes and Abeta. Proc. Natl. Acad. Sci. U.S.A. 98, 6336-6341. doi:10.1073/pnas. 101133498

Hass, M. R., and Yankner, B. A. (2005). A \{gamma\}-secretase-independent mechanism of signal transduction by the amyloid precursor protein. J. Biol. Chem. 280, 36895-36904. doi:10.1074/jbc.M502861200

He, G., Luo, W., Li, P., Remmers, C., Netzer, W. J., Hendrick, J., et al. (2010). Gammasecretase activating protein is a therapeutic target for Alzheimer's disease. Nature 467, 95-98. doi:10.1038/nature09325

Hebert, S. S., Serneels, L., Tolia, A., Craessaerts, K., Derks, C., Filippov, M. A., et al. (2006). Regulated intramembrane proteolysis of amyloid precursor protein and regulation of expression of putative target genes. EMBO Rep. 7, 739-745. doi:10.1038/sj.embor.7400704

Helisalmi, S., Hiltunen, M., Vepsalainen, S., Iivonen, S., Mannermaa, A., Lehtovirta, M., et al. (2004). Polymorphisms in neprilysin gene affect the risk of Alzheimer's disease in Finnish patients. J. Neurol. Neurosurg. Psychiatr. 75, 1746-1748. doi:10.1136/jnnp.2004.036574

Hellstrom-Lindahl, E., Ravid, R., and Nordberg, A. (2008). Age-dependent decline of neprilysin in Alzheimer's disease and normal brain: inverse correlation with Abeta levels. Neurobiol. Aging 29, 210-221. doi:10.1016/j.neurobiolaging.2006. 10.010

Hendrickx, A., Pierrot, N., Tasiaux, B., Schakman, O., Brion, J. P., KienlenCampard, P., et al. (2013). Epigenetic induction of EGR-1 expression by the amyloid precursor protein during exposure to novelty. PLOS ONE 8:e74305. doi:10.1371/journal.pone.0074305

Hendriks, L., van Duijn, C. M., Cras, P., Cruts, M., Van Hul, W., van Harskamp, F., et al. (1992). Presenile dementia and cerebral haemorrhage linked to a mutation at codon 692 of the beta-amyloid precursor protein gene. Nat. Genet. 1, 218-221. doi:10.1038/ng0692-218

Herms, J., Anliker, B., Heber, S., Ring, S., Fuhrmann, M., Kretzschmar, H., et al. (2004). Cortical dysplasia resembling human type 2 lissencephaly in mice lacking all three APP family members. EMBO J. 23, 4106-4115. doi:10.1038/sj.emboj. 7600390

Hersh, L. B., and Rodgers, D. W. (2008). Neprilysin and amyloid beta peptide degradation. Curr. Alzheimer Res. 5, 225-231. doi:10.2174/156720508783954703

Hickman, S. E., Allison, E. K., and El Khoury, J. (2008). Microglial dysfunction and defective beta-amyloid clearance pathways in aging Alzheimer's disease mice. J. Neurosci. 28, 8354-8360. doi:10.1523/JNEUROSCI.0616-08.2008

Hicks, D. A., Makova, N. Z., Gough, M., Parkin, E. T., Nalivaeva, N. N., and Turner, A. J. (2013). The amyloid precursor protein represses expression of acetylcholinesterase in neuronal cell lines. J. Biol. Chem. 288, 26039-26051. doi:10.1074/jbc.M113.461269

Hong, Y., Beckett, C., Belyaev, N. D., and Turner, A. J. (2012). The impact of amyloid precursor protein signalling and histone deacetylase inhibition on neprilysin expression in human prostate cells. Int. J. Cancer 130, 775-786. doi:10.1002/ijc.26028

Hooper, N. M., and Turner, A. J. (2002). The search for alpha-secretase and its potential as a therapeutic approach to Alzheimer s disease. Curr. Med. Chem. 9, 1107-1119. doi:10.2174/0929867023370121

Hoshi, M., Sato, M., Matsumoto, S., Noguchi, A., Yasutake, K., Yoshida, N., et al. (2003). Spherical aggregates of beta-amyloid (amylospheroid) show high neurotoxicity and activate tau protein kinase I/glycogen synthase kinase-3beta. Proc. Natl. Acad. Sci. U.S.A. 100, 6370-6375. doi:10.1073/pnas.1237107100

Howell, S., Nalbantoglu, J., and Crine, P. (1995). Neutral endopeptidase can hydrolyze beta-amyloid(1-40) but shows no effect on beta-amyloid precursor protein metabolism. Peptides 16,647-652. doi:10.1016/0196-9781(95) 00021-B

Huang, J., Guan, H., Booze, R. M., Eckman, C. B., and Hersh, L. B. (2004). Estrogen regulates neprilysin activity in rat brain. Neurosci. Lett. 367, 85-87. doi:10.1016/j.neulet.2004.05.085

Huang, S. M., Mouri, A., Kokubo, H., Nakajima, R., Suemoto, T., Higuchi, M., et al. (2006). Neprilysin-sensitive synapse-associated amyloid-beta peptide oligomers impair neuronal plasticity and cognitive function. J. Biol. Chem. 281, 17941-17951. doi:10.1074/jbc.M601372200 
Huysseune, S., Kienlen-Campard, P., Hebert, S., Tasiaux, B., Leroy, K., Devuyst, O., et al. (2009). Epigenetic control of aquaporin 1 expression by the amyloid precursor protein. FASEB J. 23, 4158-4167. doi:10.1096/fj.09-140012

Iijima-Ando, K., Hearn, S. A., Granger, L., Shenton, C., Gatt, A., Chiang, H. C., et al. (2008). Overexpression of neprilysin reduces Alzheimer amyloid-beta42 (Abeta42)-induced neuron loss and intraneuronal Abeta42 deposits but causes a reduction in cAMP-responsive element-binding protein-mediated transcription, age-dependent axon pathology, and premature death in Drosophila. J. Biol. Chem. 283, 19066-19076. doi:10.1074/jbc.M710509200

Ikura, T., Ogryzko, V. V., Grigoriev, M., Groisman, R., Wang, J., Horikoshi, M., et al. (2000). Involvement of the TIP60 histone acetylase complex in DNA repair and apoptosis. Cell 102, 463-473. doi:10.1016/S0092-8674(00)00051-9

Iwata, N., Mizukami, H., Shirotani, K., Takaki, Y., Muramatsu, S., Lu, B., et al. (2004). Presynaptic localization of neprilysin contributes to efficient clearance of amyloid-beta peptide in mouse brain. J. Neurosci. 24, 991-998. doi:10.1523/ JNEUROSCI.4792-03.2004

Iwata, N., Sekiguchi, M., Hattori, Y., Takahashi, A., Asai, M., Ji, B., et al. (2013). Global brain delivery of neprilysin gene by intravascular administration of AAV vector in mice. Sci. Rep. 3, 1472. doi:10.1038/srep01472

Iwata, N., Takaki, Y., Fukami, S., Tsubuki, S., and Saido, T. C. (2002). Region-specific reduction of Abeta-degrading endopeptidase, neprilysin, in mouse hippocampus upon aging. J. Neurosci. Res. 70, 493-500. doi:10.1002/jnr.10390

Iwata, N., Tsubuki, S., Takaki, Y., Shirotani, K., Lu, B., Gerard, N. P., et al. (2001). Metabolic regulation of brain Abeta by neprilysin. Science 292, 1550-1552. doi:10.1126/science.1059946

Iwata, N., Tsubuki, S., Takaki, Y., Watanabe, K., Sekiguchi, M., Hosoki, E., et al. (2000). Identification of the major Abeta1-42-degrading catabolic pathway in brain parenchyma: suppression leads to biochemical and pathological deposition. Nat. Med. 6, 143-150. doi:10.1038/72237

Iwatsubo, T., Odaka, A., Suzuki, N., Mizusawa, H., Nukina, N., and Ihara, Y. (1994). Visualization of Abeta 42(43) and Abeta 40 in senile plaques with end-specific Abeta monoclonals: evidence that an initially deposited species is Abeta 42(43). Neuron 13, 45-53. doi:10.1016/0896-6273(94)90458-8

Kametani, F., Tanaka, K., Ishii, T., Ikeda, S., Kennedy, H. E., and Allsop, D. (1993). Secretory form of Alzheimer amyloid precursor protein 695 in human brain lacks beta/A4 amyloid immunoreactivity. Biochem. Biophys. Res. Commun. 191, 392-398. doi:10.1006/bbrc.1993.1230

Kanemitsu, H., Tomiyama, T., and Mori, H. (2003). Human neprilysin is capable of degrading amyloid beta peptide not only in the monomeric form but also the pathological oligomeric form. Neurosci. Lett. 350, 113-116. doi:10.1016/S03043940(03)00898-X

Kang, D. E., Pietrzik, C. U., Baum, L., Chevallier, N., Merriam, D. E., Kounnas, M. Z., et al. (2000). Modulation of amyloid beta-protein clearance and Alzheimer's disease susceptibility by the LDL receptor-related protein pathway. J. Clin. Invest. 106, 1159-1166. doi:10.1172/JCI11013

Kang, J., Lemaire, H. G., Unterbeck, A., Salbaum, J. M., Masters, C. L., Grzeschik, K. H., et al. (1987). The precursor of Alzheimer's disease amyloid A4 protein resembles a cell-surface receptor. Nature 325, 733-736. doi:10.1038/ 325733a0

Kim, H. S., Kim, E. M., Lee, J. P., Park, C. H., Kim, S., Seo, J. H., et al. (2003). C-terminal fragments of amyloid precursor protein exert neurotoxicity by inducing glycogen synthase kinase-3beta expression. FASEB J. 17, 1951-1953. doi:10.1096/fj.03-0106fje

Kimberly, W. T., LaVoie, M. J., Ostaszewski, B. L., Ye, W., Wolfe, M. S., and Selkoe, D. J. (2003). Gamma-secretase is a membrane protein complex comprised of presenilin, nicastrin, Aph-1, and Pen-2. Proc. Natl. Acad. Sci. U.S.A. 100, 6382-6387. doi:10.1073/pnas.1037392100

Kimberly, W. T., Zheng, J. B., Guenette, S. Y., and Selkoe, D. J. (2001). The intracellular domain of the beta-amyloid precursor protein is stabilized by Fe65 and translocates to the nucleus in a Notch-like manner. J. Biol. Chem. 276, 40288-40292. doi:10.1074/jbc.C100447200

Kinoshita, A., Whelan, C. M., Smith, C. J., Berezovska, O., and Hyman, B. T. (2002). Direct visualization of the gamma secretase-generated carboxyl-terminal domain of the amyloid precursor protein: association with Fe65 and translocation to the nucleus. J. Neurochem. 82, 839-847. doi:10.1046/j.1471-4159.2002. 01016.x

Kitao, Y., Ozawa, K., Miyazaki, M., Tamatani, M., Kobayashi, T., Yanagi, H., et al. (2001). Expression of the endoplasmic reticulum molecular chaperone
(ORP150) rescues hippocampal neurons from glutamate toxicity. J. Clin. Invest. 108, 1439-1450. doi:10.1172/JCI200112978

Klein, C., Patte-Mensah, C., Taleb, O., Bourguignon, J. J., Schmitt, M., Bihel, F., et al. (2013). The neuroprotector kynurenic acid increases neuronal cell survival through neprilysin induction. Neuropharmacology 70, 254-260. doi:10.1016/j. neuropharm.2013.02.006

Kogel, D., Concannon, C. G., Muller, T., Konig, H., Bonner, C., Poeschel, S., et al. (2012). The APP intracellular domain (AICD) potentiates ER stress-induced apoptosis. Neurobiol. Aging 33, 2200-2209. doi:10.1016/j.neurobiolaging.2011. 06.012

Konietzko, U., Goodger, Z. V., Meyer, M., Kohli, B. M., Bosset, J., Lahiri, D. K., et al. (2010). Co-localization of the amyloid precursor protein and Notch intracellular domains in nuclear transcription factories. Neurobiol. Aging 31, 58-73. doi:10.1016/j.neurobiolaging.2008.03.001

Kopan, R., and Turner, D. L. (1996). The Notch pathway: democracy and aristocracy in the selection of cell fate. Curr. Opin. Neurobiol. 6, 594-601. doi:10.1016/ S0959-4388(96)80090-0

Kowalska, A. (2004). Genetic basis of neurodegeneration in familial Alzheimer's disease. Pol. J. Pharmacol. 56, 171-178.

Kume, H., Maruyama, K., and Kametani, F. (2004). Intracellular domain generation of amyloid precursor protein by epsilon-cleavage depends on C-terminal fragment by alpha-secretase cleavage. Int. J. Mol. Med. 13, 121-125.

Kuro-o, M., Matsumura, Y., Aizawa, H., Kawaguchi, H., Suga, T., Utsugi, T., et al. (1997). Mutation of the mouse Klotho gene leads to a syndrome resembling ageing. Nature 390, 45-51. doi:10.1038/36285

Kurosu, H., Yamamoto, M., Clark, J. D., Pastor, J. V., Nandi, A., Gurnani, P., et al. (2005). Suppression of aging in mice by the hormone Klotho. Science 309, 1829-1833. doi:10.1126/science.1112766

Lai, A., Gibson, A., Hopkins, C. R., and Trowbridge, I. S. (1998). Signal-dependent trafficking of beta-amyloid precursor protein-transferrin receptor chimeras in Madin-Darby canine kidney cells. J. Biol. Chem. 273, 3732-3739. doi:10.1074/ jbc.273.6.3732

Lam, F. C., Liu, R., Lu, P., Shapiro, A. B., Renoir, J. M., Sharom, F. J., et al. (2001). beta-Amyloid efflux mediated by p-glycoprotein. J. Neurochem. 76, 1121-1128. doi:10.1046/j.1471-4159.2001.00113.x

Lambert, M. P., Barlow, A. K., Chromy, B. A., Edwards, C., Freed, R., Liosatos, M., et al. (1998). Diffusible, nonfibrillar ligands derived from Abeta1-42 are potent central nervous system neurotoxins. Proc. Natl. Acad. Sci. U.S.A. 95, 6448-6453. doi:10.1073/pnas.95.11.6448

Lammich, S., Kojro, E., Postina, R., Gilbert, S., Pfeiffer, R., Jasionowski, M., et al. (1999). Constitutive and regulated alpha-secretase cleavage of Alzheimer's amyloid precursor protein by a disintegrin metalloprotease. Proc. Natl. Acad. Sci. U.S.A. 96, 3922-3927. doi:10.1073/pnas.96.7.3922

Lashuel, H. A., Hartley, D., Petre, B. M., Walz, T., and Lansbury, P. T. Jr. (2002). Neurodegenerative disease: amyloid pores from pathogenic mutations. Nature 418, 291. doi:10.1038/418291a

Lau, K. F., Chan, W. M., Perkinton, M. S., Tudor, E. L., Chang, R. C., Chan, H. Y., et al. (2008). Dexras1 interacts with FE65 to regulate FE65-amyloid precursor protein-dependent transcription. J. Biol. Chem. 283, 34728-34737. doi:10.1074/jbc.M801874200

Lauderback, C. M., Hackett, J. M., Huang, F. F., Keller, J. N., Szweda, L. I., Markesbery, W. R., et al. (2001). The glial glutamate transporter, GLT-1, is oxidatively modified by 4-hydroxy-2-nonenal in the Alzheimer's disease brain: the role of Abeta1-42. J. Neurochem. 78, 413-416. doi:10.1046/j.1471-4159.2001.00451.x

Lee, M. R., Lee, D., Shin, S. K., Kim, Y. H., and Choi, C. Y. (2008). Inhibition of APP intracellular domain (AICD) transcriptional activity via covalent conjugation with Nedd8. Biochem. Biophys. Res. Commun. 366, 976-981. doi:10.1016/j.bbrc.2007.12.066

Leissring, M. A., Farris, W., Chang, A. Y., Walsh, D. M., Wu, X., Sun, X., et al. (2003). Enhanced proteolysis of beta-amyloid in APP transgenic mice prevents plaque formation, secondary pathology, and premature death. Neuron 40, 1087-1093. doi:10.1016/S0896-6273(03)00787-6

Letarte, M., Vera, S., Tran, R., Addis, J. B., Onizuka, R. J., Quackenbush, E. J., et al. (1988). Common acute lymphocytic leukemia antigen is identical to neutral endopeptidase. J. Exp. Med. 168, 1247-1253. doi:10.1084/jem.168.4.1247

Li, C., Booze, R. M., and Hersh, L. B. (1995). Tissue-specific expression of rat neutral endopeptidase (neprilysin) mRNAs. J. Biol. Chem. 270, 5723-5728. doi:10.1074/jbc.270.11.5723 
Li, H., Wang, B., Wang, Z., Guo, Q., Tabuchi, K., Hammer, R. E., et al. (2010). Soluble amyloid precursor protein (APP) regulates transthyretin and Klotho gene expression without rescuing the essential function of APP. Proc. Natl. Acad. Sci. U.S.A. 107, 17362-17367. doi:10.1073/pnas.1012568107

Liang, K., Yang, L., Yin, C., Xiao, Z., Zhang, J., Liu, Y., et al. (2010). Estrogen stimulates degradation of beta-amyloid peptide by up-regulating neprilysin. J. Biol. Chem. 285, 935-942. doi:10.1074/jbc.M109.051664

Lichtenthaler, S. F., Haass, C., and Steiner, H. (2011). Regulated intramembrane proteolysis - lessons from amyloid precursor protein processing. J. Neurochem. 117, 779-796. doi:10.1111/j.1471-4159.2011.07248.x

Liu, Q., Zerbinatti, C. V., Zhang, J., Hoe, H. S., Wang, B., Cole, S. L., et al. (2007). Amyloid precursor protein regulates brain apolipoprotein E and cholesterol metabolism through lipoprotein receptor LRP1. Neuron 56, 66-78. doi:10.1016/j.neuron.2007.08.008

Llewellyn, D. J., Lang, I. A., Langa, K. M., and Melzer, D. (2011). Vitamin D and cognitive impairment in the elderly U.S. population. J. Gerontol. A Biol. Sci. Med. Sci. 66, 59-65. doi:10.1093/gerona/glq185

Logeat, F., Bessia, C., Brou, C., LeBail, O., Jarriault, S., Seidah, N. G., et al. (1998). The Notch1 receptor is cleaved constitutively by a furin-like convertase. Proc. Natl. Acad. Sci. U.S.A. 95, 8108-8112. doi:10.1073/pnas.95.14.8108

Lorent, K., Overbergh, L., Moechars, D., De Strooper, B., Van Leuven, F., and Van den Berghe, H. (1995). Expression in mouse embryos and in adult mouse brain of three members of the amyloid precursor protein family, of the alpha2-macroglobulin receptor/low density lipoprotein receptor-related protein and of its ligands apolipoprotein E, lipoprotein lipase, alpha-2-macroglobulin and the 40,000 molecular weight receptor-associated protein. Neuroscience 65, 1009-1025.

Lu, B., Gerard, N. P., Kolakowski, L. F. Jr., Bozza, M., Zurakowski, D., Finco, O., et al. (1995). Neutral endopeptidase modulation of septic shock. J. Exp. Med. 181, 2271-2275. doi:10.1084/jem.181.6.2271

Lu, D. C., Rabizadeh, S., Chandra, S., Shayya, R. F., Ellerby, L. M., Ye, X., et al. (2000). A second cytotoxic proteolytic peptide derived from amyloid beta-protein precursor. Nat. Med. 6, 397-404. doi:10.1038/74656

Lu, T., Pan, Y., Kao, S. Y., Li, C., Kohane, I., Chan, J., et al. (2004). Gene regulation and DNA damage in the ageing human brain. Nature 429, 883-891. doi:10.1038/nature02661

Madani, R., Poirier, R., Wolfer, D. P., Welzl, H., Groscurth, P., Lipp, H. P., et al. (2006). Lack of neprilysin suffices to generate murine amyloid-like deposits in the brain and behavioral deficit in vivo. J. Neurosci. Res. 84, 1871-1878. doi:10.1002/jnr.21074

Malfroy, B., Kuang, W. J., Seeburg, P. H., Mason, A. J., and Schofield, P. R. (1988). Molecular cloning and amino acid sequence of human enkephalinase (neutral endopeptidase). FEBS Lett. 229, 206-210. doi:10.1016/0014-5793(88) 80828-7

Maloney, B., and Lahiri, D. K. (2011). The Alzheimer's amyloid beta-peptide (Abeta) binds a specific DNA Abeta-interacting domain (AbetaID) in the APP, BACE1, and APOE promoters in a sequence-specific manner: characterizing a new regulatory motif. Gene 488, 1-12. doi:10.1016/j.gene.2011.06.004

Manly, J. J., Merchant, C. A., Jacobs, D. M., Small, S. A., Bell, K., Ferin, M., et al. (2000). Endogenous estrogen levels and Alzheimer's disease among postmenopausal women. Neurology 54, 833-837. doi:10.1212/WNL.54.4.833

Marr, R. A., Rockenstein, E., Mukherjee, A., Kindy, M. S., Hersh, L. B., Gage, F. H., et al. (2003). Neprilysin gene transfer reduces human amyloid pathology in transgenic mice. J. Neurosci. 23, 1992-1996.

Maruyama, M., Higuchi, M., Takaki, Y., Matsuba, Y., Tanji, H., Nemoto, M., et al. (2005). Cerebrospinal fluid neprilysin is reduced in prodromal Alzheimer's disease. Ann. Neurol. 57, 832-842. doi:10.1002/ana.20494

Masters, C. L., Simms, G., Weinman, N. A., Multhaup, G., McDonald, B. L., and Beyreuther, K. (1985). Amyloid plaque core protein in Alzheimer disease and Down syndrome. Proc. Natl. Acad. Sci. U.S.A. 82, 4245-4249. doi:10.1073/pnas. 82.12.4245

Matsas, R., Kenny, A. J., and Turner, A. J. (1984). The metabolism of neuropeptides. The hydrolysis of peptides, including enkephalins, tachykinins and their analogues, by endopeptidase-24.11. Biochem. J. 223, 433-440.

Matsas, R., Kenny, A. J., and Turner, A. J. (1986). An immunohistochemical study of endopeptidase-24.11 ("enkephalinase") in the pig nervous system. Neuroscience 18, 991-1012. doi:10.1016/0306-4522(86)90113-2
Mawuenyega, K. G., Sigurdson, W., Ovod, V., Munsell, L., Kasten, T., Morris, J. C., et al. (2010). Decreased clearance of CNS beta-amyloid in Alzheimer's disease. Science 330, 1774. doi:10.1126/science.1197623

McLoughlin, D. M., and Miller, C. C. (2008). The FE65 proteins and Alzheimer's disease. J. Neurosci. Res. 86, 744-754. doi:10.1002/jnr.21532

Meilandt, W. J., Cisse, M., Ho, K., Wu, T., Esposito, L. A., Scearce-Levie, K., et al. (2009). Neprilysin overexpression inhibits plaque formation but fails to reduce pathogenic Abeta oligomers and associated cognitive deficits in human amyloid precursor protein transgenic mice. J. Neurosci. 29, 1977-1986. doi:10.1523/JNEUROSCI.2984-08.2009

Melzig, M. F., and Janka, M. (2003). Enhancement of neutral endopeptidase activity in SK-N-SH cells by green tea extract. Phytomedicine 10, 494-498. doi:10.1078/094471103322331449

Miners, J. S., Baig, S., Tayler, H., Kehoe, P. G., and Love, S. (2009). Neprilysin and insulin-degrading enzyme levels are increased in Alzheimer disease in relation to disease severity. J. Neuropathol. Exp. Neurol. 68, 902-914. doi:10.1097/NEN. 0b013e3181afe475

Miners, J. S., Barua, N., Kehoe, P. G., Gill, S., and Love, S. (2011). Abeta-degrading enzymes: potential for treatment of Alzheimer disease. J. Neuropathol. Exp. Neurol. 70, 944-959. doi:10.1097/NEN.0b013e3182345e46

Miners, J. S., Van Helmond, Z., Chalmers, K., Wilcock, G., Love, S., and Kehoe, P. G. (2006). Decreased expression and activity of neprilysin in Alzheimer disease are associated with cerebral amyloid angiopathy. J. Neuropathol. Exp. Neurol. 65, 1012-1021. doi:10.1097/01.jnen.0000240463.87886.9a

Miners, J. S., Verbeek, M. M., Rikkert, M. O., Kehoe, P. G., and Love, S. (2008). Immunocapture-based fluorometric assay for the measurement of neprilysinspecific enzyme activity in brain tissue homogenates and cerebrospinal fluid. J. Neurosci. Methods 167, 229-236. doi:10.1016/j.jneumeth.2007.08.012

Muller, T., Concannon, C. G., Ward, M. W., Walsh, C. M., Tirniceriu, A. L., Tribl, F., et al. (2007). Modulation of gene expression and cytoskeletal dynamics by the amyloid precursor protein intracellular domain (AICD). Mol. Biol. Cell 18, 201-210. doi:10.1091/mbc.E06-04-0283

Muller, T., Meyer, H. E., Egensperger, R., and Marcus, K. (2008). The amyloid precursor protein intracellular domain (AICD) as modulator of gene expression, apoptosis, and cytoskeletal dynamics-relevance for Alzheimer's disease. Prog. Neurobiol. 85, 393-406. doi:10.1016/j.pneurobio.2008.05.002

Muller, T., Schrotter, A., Loosse, C., Pfeiffer, K., Theiss, C., Kauth, M., et al. (2013). A ternary complex consisting of AICD, FE65, and TIP60 down-regulates Stathmin1. Biochim. Biophys. Acta 1834, 387-394. doi:10.1016/j.bbapap.2012.07. 017

Mumm, J. S., Schroeter, E. H., Saxena, M. T., Griesemer, A., Tian, X., Pan, D. J., et al. (2000). A ligand-induced extracellular cleavage regulates gamma-secretaselike proteolytic activation of Notch1. Mol. Cell 5, 197-206. doi:10.1016/S10972765(00)80416-5

Musa, A., Lehrach, H., and Russo, V. A. (2001). Distinct expression patterns of two zebrafish homologues of the human APP gene during embryonic development. Dev. Genes Evol. 211, 563-567. doi:10.1007/s00427-001-0189-9

Nakaya, T., and Suzuki, T. (2006). Role of APP phosphorylation in FE65-dependent gene transactivation mediated by AICD. Genes Cells 11, 633-645. doi:10.1111/j. 1365-2443.2006.00968.x

Nalivaeva, N. N., Belyaev, N. D., Lewis, D. I., Pickles, A. R., Makova, N. Z., Bagrova, D. I., et al. (2012). Effect of sodium valproate administration on brain neprilysin expression and memory in rats. J. Mol. Neurosci. 46, 569-577. doi:10.1007/s12031-011-9644-x

Niikura, T., Sidahmed, E., Hirata-Fukae, C., Aisen, P. S., and Matsuoka, Y. (2011). A humanin derivative reduces amyloid beta accumulation and ameliorates memory deficit in triple transgenic mice. PLOS ONE 6:e16259. doi:10.1371/journal. pone.0016259

Nilsberth, C., Westlind-Danielsson, A., Eckman, C. B., Condron, M. M., Axelman, K., Forsell, C., et al. (2001). The 'Arctic' APP mutation (E693G) causes Alzheimer's disease by enhanced Abeta protofibril formation. Nat. Neurosci. 4, 887-893. doi:10.1038/nn0901-887

Nunan, J., Williamson, N. A., Hill, A. F., Sernee, M. F., Masters, C. L., and Small, D. H. (2003). Proteasome-mediated degradation of the C-terminus of the Alzheimer's disease beta-amyloid protein precursor: effect of C-terminal truncation on production of beta-amyloid protein. J. Neurosci. Res. 74, 378-385. doi:10.1002/jnr.10646 
Oda, M., Morino, H., Maruyama, H., Terasawa, H., Izumi, Y., Torii, T., et al. (2002). Dinucleotide repeat polymorphisms in the neprilysin gene are not associated with sporadic Alzheimer's disease. Neurosci. Lett. 320, 105-107. doi:10.1016/S0304-3940(02)00057-5

Oefner, C., D’Arcy, A., Hennig, M., Winkler, F. K., and Dale, G. E. (2000). Structure of human neutral endopeptidase (Neprilysin) complexed with phosphoramidon. J. Mol. Biol. 296, 341-349. doi:10.1006/jmbi.1999.3492

Ohyagi, Y., Asahara, H., Chui, D. H., Tsuruta, Y., Sakae, N., Miyoshi, K., et al. (2005). Intracellular Abeta42 activates p53 promoter: a pathway to neurodegeneration in Alzheimer's disease. FASEB J. 19, 255-257. doi:10.1096/fj.04-2637fje

Ozaki, T., Li, Y., Kikuchi, H., Tomita, T., Iwatsubo, T., and Nakagawara, A. (2006). The intracellular domain of the amyloid precursor protein (AICD) enhances the p53-mediated apoptosis. Biochem. Biophys. Res. Commun. 351, 57-63. doi:10.1016/j.bbrc.2006.09.162

Papandreou, C. N., Usmani, B., Geng, Y., Bogenrieder, T., Freeman, R., Wilk, S., et al. (1998). Neutral endopeptidase 24.11 loss in metastatic human prostate cancer contributes to androgen-independent progression. Nat. Med. 4, 50-57. doi:10.1038/nm0198-050

Pardossi-Piquard, R., Dunys, J., Kawarai, T., Sunyach, C., Alves da Costa, C., Vincent, B., et al. (2007). Response to correspondence: Pardossi-Piquard et al., "Presenilin-dependent transcriptional control of the Abeta-degrading enzyme neprilysin by intracellular domains of betaAPP and APLP.” Neuron 46, 541-554. Neuron 53, 483-486. doi:10.1016/j.neuron.2007.01.024

Pardossi-Piquard, R., Dunys, J., Yu, G., St George-Hyslop, P., Alves da Costa, C., and Checler, F. (2006). Neprilysin activity and expression are controlled by nicastrin. J. Neurochem. 97, 1052-1056. doi:10.1111/j.1471-4159.2006.03822.x

Pardossi-Piquard, R., Petit, A., Kawarai, T., Sunyach, C., Alves da Costa, C., Vincent, B., et al. (2005). Presenilin-dependent transcriptional control of the Abetadegrading enzyme neprilysin by intracellular domains of betaAPP and APLP. Neuron 46, 541-554. doi:10.1016/j.neuron.2005.04.008

Park, M. H., Lee, J. K., Choi, S., Ahn, J., Jin, H. K., Park, J. S., et al. (2013). Recombinant soluble neprilysin reduces amyloid-beta accumulation and improves memory impairment in Alzheimer's disease mice. Brain Res. 1529, 113-124. doi:10.1016/j.brainres.2013.05.045

Parvathy, S., Hussain, I., Karran, E. H., Turner, A. J., and Hooper, N. M. (1999). Cleavage of Alzheimer's amyloid precursor protein by alpha-secretase occurs at the surface of neuronal cells. Biochemistry 38, 9728-9734. doi:10.1021/bi9906827

Passer, B., Pellegrini, L., Russo, C., Siegel, R. M., Lenardo, M. J., Schettini, G., et al. (2000). Generation of an apoptotic intracellular peptide by gamma-secretase cleavage of Alzheimer's amyloid beta protein precursor. J. Alzheimers Dis. 2, 289-301.

Petanceska, S. S., Nagy, V., Frail, D., and Gandy, S. (2000). Ovariectomy and 17betaestradiol modulate the levels of Alzheimer's amyloid beta peptides in brain. Neurology 54, 2212-2217. doi:10.1212/WNL.54.12.2212

Piedrahita, D., Hernandez, I., Lopez-Tobon, A., Fedorov, D., Obara, B., Manjunath, B. S., et al. (2010). Silencing of CDK5 reduces neurofibrillary tangles in transgenic Alzheimer's mice. J. Neurosci. 30, 13966-13976. doi:10.1523/JNEUROSCI. 3637- 10.2010

Pierrot, N., Tyteca, D., D’Auria, L., Dewachter, I., Gailly, P., Hendrickx, A., et al. (2013). Amyloid precursor protein controls cholesterol turnover needed for neuronal activity. EMBO Mol. Med. 5, 608-625. doi:10.1002/emmm.201202215

Poirier, R., Wolfer, D. P., Welzl, H., Tracy, J., Galsworthy, M. J., Nitsch, R. M., et al. (2006). Neuronal neprilysin overexpression is associated with attenuation of Abeta-related spatial memory deficit. Neurobiol. Dis. 24, 475-483. doi:10.1016/j.nbd.2006.08.003

Preston, S. D., Steart, P. V., Wilkinson, A., Nicoll, J. A., and Weller, R. O. (2003). Capillary and arterial cerebral amyloid angiopathy in Alzheimer's disease: defining the perivascular route for the elimination of amyloid beta from the human brain. Neuropathol. Appl. Neurobiol. 29, 106-117. doi:10.1046/j.1365-2990.2003. 00424.x

Qing, H., He, G., Ly, P. T., Fox, C. J., Staufenbiel, M., Cai, F., et al. (2008). Valproic acid inhibits Abeta production, neuritic plaque formation, and behavioral deficits in Alzheimer's disease mouse models. J. Exp. Med. 205, 2781-2789. doi:10.1084/jem.20081588

Qi-Takahara, Y., Morishima-Kawashima, M., Tanimura, Y., Dolios, G., Hirotani, N., Horikoshi, Y., et al. (2005). Longer forms of amyloid beta protein: implications for the mechanism of intramembrane cleavage by gamma-secretase. J. Neurosci. 25, 436-445. doi:10.1523/JNEUROSCI.1575-04.2005
Rajendran, L., Honsho, M., Zahn, T. R., Keller, P., Geiger, K. D., Verkade, P., et al. (2006). Alzheimer's disease beta-amyloid peptides are released in association with exosomes. Proc. Natl. Acad. Sci. U.S.A. 103, 11172-11177. doi:10.1073/pnas. 0603838103

Relton, J. M., Gee, N. S., Matsas, R., Turner, A. J., and Kenny, A. J. (1983). Purification of endopeptidase-24.11 ('enkephalinase') from pig brain by immunoadsorbent chromatography. Biochem. J. 215, 519-523.

Robinson, A., Grösgen, S., Mett, J., Zimmer, V. C., Haupenthal, V. J., Hundsdorfer, B., et al. (2013). Upregulation of PGC-1alpha expression by Alzheimer's diseaseassociated pathway: presenilin 1/amyloid precursor protein (APP)/intracellular domain of APP. Aging Cell doi:10.1111/acel.12183

Rogers, J., and Lue, L. F. (2001). Microglial chemotaxis, activation, and phagocytosis of amyloid beta-peptide as linked phenomena in Alzheimer's disease. Neurochem. Int. 39, 333-340. doi:10.1016/S0197-0186(01)00040-7

Roher, A. E., Lowenson, J. D., Clarke, S., Woods, A. S., Cotter, R. J., Gowing, E., et al. (1993). beta-Amyloid-(1-42) is a major component of cerebrovascular amyloid deposits: implications for the pathology of Alzheimer disease. Proc. Natl. Acad. Sci. U.S.A. 90, 10836-10840. doi:10.1073/pnas.90.22.10836

Roques, B. P., Noble, F., Dauge, V., Fournie-Zaluski, M. C., and Beaumont, A. (1993). Neutral endopeptidase 24.11: structure, inhibition, and experimental and clinical pharmacology. Pharmacol. Rev. 45, 87-146.

Russo, R., Borghi, R., Markesbery, W., Tabaton, M., and Piccini, A. (2005). Neprylisin decreases uniformly in Alzheimer's disease and in normal aging. FEBS Lett. 579, 6027-6030. doi:10.1016/j.febslet.2005.09.054

Ryan, K. A., and Pimplikar, S. W. (2005). Activation of GSK-3 and phosphorylation of CRMP2 in transgenic mice expressing APP intracellular domain. J. Cell Biol. 171, 327-335. doi:10.1083/jcb.200505078

Ryan, M. M., Morris, G. P., Mockett, B. G., Bourne, K., Abraham, W. C., Tate, W. P., et al. (2013). Time-dependent changes in gene expression induced by secreted amyloid precursor protein-alpha in the rat hippocampus. BMC Genomics 14:376. doi:10.1186/1471-2164-14-376

Sagare, A., Deane, R., Bell, R. D., Johnson, B., Hamm, K., Pendu, R., et al. (2007). Clearance of amyloid-beta by circulating lipoprotein receptors. Nat. Med. 13, 1029-1031. doi:10.1038/nm1635

Sagare, A. P., Deane, R., and Zlokovic, B. V. (2012). Low-density lipoprotein receptorrelated protein 1: a physiological Abeta homeostatic mechanism with multiple therapeutic opportunities. Pharmacol. Ther. 136, 94-105. doi:10.1016/j. pharmthera.2012.07.008

Saido, T., and Leissring, M. A. (2012). Proteolytic degradation of amyloid betaprotein. Cold Spring Harb. Perspect. Med. 2, a006379. doi:10.1101/cshperspect. a006379

Saito, T., Iwata, N., Tsubuki, S., Takaki, Y., Takano, J., Huang, S. M., et al. (2005). Somatostatin regulates brain amyloid beta peptide Abeta42 through modulation of proteolytic degradation. Nat. Med. 11, 434-439. doi:10.1038/nm1206

Sandbrink, R., Masters, C. L., and Beyreuther, K. (1994). Beta A4-amyloid protein precursor mRNA isoforms without exon 15 are ubiquitously expressed in rat tissues including brain, but not in neurons. J. Biol. Chem. 269, 1510-1517.

Sandoval, K. E., Farr, S. A., Banks, W. A., Crider, A. M., Morley, J. E., and Witt, K. A. (2012). Somatostatin receptor subtype-4 agonist NNC 26-9100 decreases extracellular and intracellular Abeta(1)(-)(4)(2) trimers. Eur. J. Pharmacol. 683, 116-124. doi:10.1016/j.ejphar.2012.03.020

Sastre, M., Steiner, H., Fuchs, K., Capell, A., Multhaup, G., Condron, M. M., et al. (2001). Presenilin-dependent gamma-secretase processing of beta-amyloid precursor protein at a site corresponding to the S3 cleavage of Notch. EMBO Rep. 2, 835-841. doi:10.1093/embo-reports/kve180

Savage, M. J., Trusko, S. P., Howland, D. S., Pinsker, L. R., Mistretta, S., Reaume, A. G., et al. (1998). Turnover of amyloid beta-protein in mouse brain and acute reduction of its level by phorbol ester. J. Neurosci. 18, 1743-1752.

Scheinfeld, M. H., Matsuda, S., and D'Adamio, L. (2003). JNK-interacting protein-1 promotes transcription of Abeta protein precursor but not Abeta precursor-like proteins, mechanistically different than Fe65. Proc. Natl. Acad. Sci. U.S.A. 100, 1729-1734. doi:10.1073/pnas.0437908100

Scheuner, D., Eckman, C., Jensen, M., Song, X., Citron, M., Suzuki, N., et al. (1996). Secreted amyloid beta-protein similar to that in the senile plaques of Alzheimer's disease is increased in vivo by the presenilin 1 and 2 and APP mutations linked to familial Alzheimer's disease. Nat. Med. 2, 864-870. doi:10.1038/nm0896-864 Schrenk-Siemens, K., Perez-Alcala, S., Richter, J., Lacroix, E., Rahuel, J., Korte, M., et al. (2008). Embryonic stem cell-derived neurons as a cellular system to study 
gene function: lack of amyloid precursor proteins APP and APLP2 leads to defective synaptic transmission. Stem Cells 26, 2153-2163. doi:10.1634/stemcells. 2008-0010

Schroeter, E. H., Kisslinger, J. A., and Kopan, R. (1998). Notch-1 signalling requires ligand-induced proteolytic release of intracellular domain. Nature 393, 382-386. doi: $10.1038 / 30756$

Schwartz, J. C., de la Baume, S., Malfroy, B., Patey, G., Perdrisot, R., Swerts, J. P., et al. (1980). "Enkephalinase", a newly characterised dipeptidyl carboxypeptidase: properties and possible role in enkephalinergic transmission. Int. J. Neurol. 14, 195-204.

Schwarzman, A. L., Gregori, L., Vitek, M. P., Lyubski, S., Strittmatter, W. J., Enghilde, J. J., et al. (1994). Transthyretin sequesters amyloid beta protein and prevents amyloid formation. Proc. Natl. Acad. Sci. U.S.A. 91, 8368-8372. doi:10.1073/pnas.91.18.8368

Selkoe, D. J. (2004). Cell biology of protein misfolding: the examples of Alzheimer's and Parkinson's diseases. Nat. Cell Biol. 6, 1054-1061. doi:10.1038/ncb1104-1054

Seubert, P., Vigo-Pelfrey, C., Esch, F., Lee, M., Dovey, H., Davis, D., et al. (1992). Isolation and quantification of soluble Alzheimer's beta-peptide from biological fluids. Nature 359, 325-327. doi:10.1038/359325a0

Shankar, G. M., Bloodgood, B. L., Townsend, M., Walsh, D. M., Selkoe, D. J., and Sabatini, B. L. (2007). Natural oligomers of the Alzheimer amyloidbeta protein induce reversible synapse loss by modulating an NMDA-type glutamate receptor-dependent signaling pathway. J. Neurosci. 27, 2866-2875. doi:10.1523/JNEUROSCI.4970-06.2007

Shibata, M., Yamada, S., Kumar, S. R., Calero, M., Bading, J., Frangione, B., et al. (2000). Clearance of Alzheimer's amyloid-ss(1-40) peptide from brain by LDL receptor-related protein-1 at the blood-brain barrier. J. Clin. Invest. 106, 1489-1499. doi:10.1172/JCI10498

Shinall, H., Song, E. S., and Hersh, L. B. (2005). Susceptibility of amyloid beta peptide degrading enzymes to oxidative damage: a potential Alzheimer's disease spiral. Biochemistry 44, 15345-15350. doi:10.1021/bi0506501

Slunt, H. H., Thinakaran, G., Von Koch, C., Lo, A. C., Tanzi, R. E., and Sisodia, S. S. (1994). Expression of a ubiquitous, cross-reactive homologue of the mouse beta-amyloid precursor protein (APP). J. Biol. Chem. 269, 2637-2644.

Sodeyama, N., Mizusawa, H., Yamada, M., Itoh, Y., Otomo, E., and Matsushita, M. (2001). Lack of association of neprilysin polymorphism with Alzheimer's disease and Alzheimer's disease-type neuropathological changes. J. Neurol. Neurosurg. Psychiatr. 71, 817-818. doi:10.1136/jnnp.71.6.817

Spencer, B., Marr, R. A., Rockenstein, E., Crews, L., Adame, A., Potkar, R., et al. (2008). Long-term neprilysin gene transfer is associated with reduced levels of intracellular Abeta and behavioral improvement in APP transgenic mice. BMC Neurosci. 9:109. doi:10.1186/1471-2202-9-109

Sprecher, C. A., Grant, F. J., Grimm, G., O’Hara, P. J., Norris, F., Norris, K., et al. (1993). Molecular cloning of the cDNA for a human amyloid precursor protein homolog: evidence for a multigene family. Biochemistry 32, 4481-4486. doi:10.1021/bi00068a002

Stein, T. D., Anders, N. J., DeCarli, C., Chan, S. L., Mattson, M. P., and Johnson, J. A. (2004). Neutralization of transthyretin reverses the neuroprotective effects of secreted amyloid precursor protein (APP) in APPSW mice resulting in tau phosphorylation and loss of hippocampal neurons: support for the amyloid hypothesis. J. Neurosci. 24, 7707-7717. doi:10.1523/JNEUROSCI.221104.2004

Sumioka, A., Nagaishi, S., Yoshida, T., Lin, A., Miura, M., and Suzuki, T. (2005). Role of 14-3-3gamma in FE65-dependent gene transactivation mediated by the amyloid beta-protein precursor cytoplasmic fragment. J. Biol. Chem. 280, 42364-42374. doi:10.1074/jbc.M504278200

Suzuki, T., and Nakaya, T. (2008). Regulation of amyloid beta-protein precursor by phosphorylation and protein interactions. J. Biol. Chem. 283, 29633-29637. doi:10.1074/jbc.R800003200

Takahashi, K., Niidome, T., Akaike, A., Kihara, T., and Sugimoto, H. (2009). Amyloid precursor protein promotes endoplasmic reticulum stress-induced cell death via C/EBP homologous protein-mediated pathway. J. Neurochem. 109, 1324-1337. doi:10.1111/j.1471-4159.2009.06067.x

Tamatani, M., Matsuyama, T., Yamaguchi, A., Mitsuda, N., Tsukamoto, Y., Taniguchi, M., et al. (2001). ORP150 protects against hypoxia/ischemia-induced neuronal death. Nat. Med. 7, 317-323. doi:10.1038/85463
Tanzi, R. E., McClatchey, A. I., Lamperti, E. D., Villa-Komaroff, L., Gusella, J. F., and Neve, R. L. (1988). Protease inhibitor domain encoded by an amyloid protein precursor mRNA associated with Alzheimer's disease. Nature 331, 528-530. doi: $10.1038 / 331528 \mathrm{a} 0$

Tanzi, R. E., Moir, R. D., and Wagner, S. L. (2004). Clearance of Alzheimer's Abeta peptide: the many roads to perdition. Neuron 43, 605-608. doi:10.1016/S08966273(04)00533-1

Tian, Y., Crump, C. J., and Li, Y. M. (2010). Dual role of alpha-secretase cleavage in the regulation of gamma-secretase activity for amyloid production. J. Biol. Chem. 285, 32549-32556. doi:10.1074/jbc.M110.128439

Tsubuki, S., Takaki, Y., and Saido, T. C. (2003). Dutch, Flemish, Italian, and Arctic mutations of APP and resistance of Abeta to physiologically relevant proteolytic degradation. Lancet 361, 1957-1958. doi:10.1016/S0140-6736(03)13555-6

Turner, A. J., Isaac, R. E., and Coates, D. (2001). The neprilysin (NEP) family of zinc metalloendopeptidases: genomics and function. Bioessays 23, 261-269. doi:10.1002/1521-1878(200103)23:3<261::AID-BIES1036>3.0.CO;2-K

Uhlik, M. T., Temple, B., Bencharit, S., Kimple, A. J., Siderovski, D. P., and Johnson, G. L. (2005). Structural and evolutionary division of phosphotyrosine binding (PTB) domains. J. Mol. Biol. 345, 1-20. doi:10.1016/j.jmb.2004.10.038

Van Broeckhoven, C., Haan, J., Bakker, E., Hardy, J. A., Van Hul, W., Wehnert, A., et al. (1990). Amyloid beta protein precursor gene and hereditary cerebral hemorrhage with amyloidosis (Dutch). Science 248, 1120-1122. doi:10.1126/ science. 1971458

Vassar, R., Bennett, B. D., Babu-Khan, S., Kahn, S., Mendiaz, E. A., Denis, P., et al. (1999). Beta-secretase cleavage of Alzheimer's amyloid precursor protein by the transmembrane aspartic protease BACE. Science 286, 735-741. doi:10.1126/science.286.5440.735

Vepsalainen, S., Helisalmi, S., Mannermaa, A., Pirttila, T., Soininen, H., and Hiltunen, M. (2009). Combined risk effects of IDE and NEP gene variants on Alzheimer disease. J. Neurol. Neurosurg. Psychiatr. 80, 1268-1270. doi:10.1136/jnnp.2008. 160002

Vingtdeux, V., Hamdane, M., Begard, S., Loyens, A., Delacourte, A., Beauvillain, J. C., et al. (2007). Intracellular $\mathrm{pH}$ regulates amyloid precursor protein intracellular domain accumulation. Neurobiol. Dis. 25, 686-696. doi:10.1016/j.nbd.2006.09. 019

Von Rotz, R. C., Kohli, B. M., Bosset, J., Meier, M., Suzuki, T., Nitsch, R. M., et al. (2004). The APP intracellular domain forms nuclear multiprotein complexes and regulates the transcription of its own precursor. J. Cell. Sci. 117(Pt 19), 4435-4448. doi:10.1242/jcs.01323

Waldron, E., Isbert, S., Kern, A., Jaeger, S., Martin, A. M., Hebert, S. S., et al. (2008). Increased AICD generation does not result in increased nuclear translocation or activation of target gene transcription. Exp. Cell Res. 314, 2419-2433. doi:10.1016/j.yexcr.2008.05.003

Walsh, D. M., Fadeeva, J. V., LaVoie, M. J., Paliga, K., Eggert, S., Kimberly, W. T., et al. (2003). gamma-Secretase cleavage and binding to FE65 regulate the nuclear translocation of the intracellular C-terminal domain (ICD) of the APP family of proteins. Biochemistry 42, 6664-6673. doi:10.1021/bi027375c

Walsh, D. M., and Selkoe, D. J. (2007). Abeta oligomers - a decade of discovery. J. Neurochem. 101, 1172-1184. doi:10.1111/j.1471-4159.2006.04426.x

Wang, D. S., Dickson, D. W., and Malter, J. S. (2006). beta-Amyloid degradation and Alzheimer's disease. J. Biomed. Biotechnol. 2006, 58406. doi:10.1155/JBB/2006/ 58406

Wang, D. S., Iwata, N., Hama, E., Saido, T. C., and Dickson, D. W. (2003). Oxidized neprilysin in aging and Alzheimer's disease brains. Biochem. Biophys. Res. Commun. 310, 236-241. doi:10.1016/j.bbrc.2003.09.003

Wang, P., Yang, G., Mosier, D. R., Chang, P., Zaidi, T., Gong, Y. D., et al. (2005a). Defective neuromuscular synapses in mice lacking amyloid precursor protein (APP) and APP-Like protein 2. J. Neurosci. 25, 1219-1225. doi:10.1523/JNEUROSCI. 4660-04.2005

Wang, D. S., Lipton, R. B., Katz, M. J., Davies, P., Buschke, H., Kuslansky, G., et al. (2005b). Decreased neprilysin immunoreactivity in Alzheimer disease, but not in pathological aging. J. Neuropathol. Exp. Neurol. 64, 378-385.

Wasco, W., Gurubhagavatula, S., Paradis, M. D., Romano, D. M., Sisodia, S. S., Hyman, B. T., et al. (1993). Isolation and characterization of APLP2 encoding a homologue of the Alzheimer's associated amyloid beta protein precursor. Nat. Genet. 5, 95-100. doi:10.1038/ng0993-95 
Weidemann, A., Eggert, S., Reinhard, F. B., Vogel, M., Paliga, K., Baier, G., et al. (2002). A novel epsilon-cleavage within the transmembrane domain of the Alzheimer amyloid precursor protein demonstrates homology with Notch processing. Biochemistry 41, 2825-2835. doi:10.1021/bi015794o

White, A. R., Du, T., Laughton, K. M., Volitakis, I., Sharples, R. A., Xilinas, M. E., et al. (2006). Degradation of the Alzheimer disease amyloid beta-peptide by metal-dependent up-regulation of metalloprotease activity. J. Biol. Chem. 281, 17670-17680. doi:10.1074/jbc.M602487200

Wiley, J. C., Smith, E. A., Hudson, M. P., Ladiges, W. C., and Bothwell, M. (2007). Fe65 stimulates proteolytic liberation of the beta-amyloid precursor protein intracellular domain. J. Biol. Chem. 282, 33313-33325. doi:10.1074/jbc.M706024200

Wood, L. S., Pickering, E. H., McHale, D., and Dechairo, B. M. (2007). Association between neprilysin polymorphisms and sporadic Alzheimer's disease. Neurosci. Lett. 427, 103-106. doi:10.1016/j.neulet.2007.09.019

$\mathrm{Xu}, \mathrm{X}$., Zhou, H., and Boyer, T. G. (2011). Mediator is a transducer of amyloidprecursor-protein-dependent nuclear signalling. EMBO Rep. 12, 216-222. doi: 10.1038/embor.2010.210

Yamamoto, T., and Horikoshi, M. (1997). Novel substrate specificity of the histone acetyltransferase activity of HIV-1-Tat interactive protein Tip60. J. Biol. Chem. 272, 30595-30598. doi:10.1074/jbc.272.49.30595

Yasojima, K., Akiyama, H., McGeer, E. G., and McGeer, P. L. (2001a). Reduced neprilysin in high plaque areas of Alzheimer brain: a possible relationship to deficient degradation of beta-amyloid peptide. Neurosci. Lett. 297, 97-100. doi:10.1016/S0304-3940(00)01675-X

Yasojima, K., McGeer, E. G., and McGeer, P. L. (2001b). Relationship between beta amyloid peptide generating molecules and neprilysin in Alzheimer disease and normal brain. Brain Res. 919, 115-121. doi:10.1016/S0006-8993(01)03008-6

Yoshikai, S., Sasaki, H., Doh-ura, K., Furuya, H., and Sakaki, Y. (1990). Genomic organization of the human amyloid beta-protein precursor gene. Gene 87, 257-263. doi:10.1016/0378-1119(90)90310-N

Yu, C., Kim, S. H., Ikeuchi, T., Xu, H., Gasparini, L., Wang, R., et al. (2001). Characterization of a presenilin-mediated amyloid precursor protein carboxyl-terminal fragment gamma. Evidence for distinct mechanisms involved in gammasecretase processing of the APP and Notchl transmembrane domains. J. Biol. Chem. 276, 43756-43760. doi:10.1074/jbc.C100410200
Zambrano, N., Minopoli, G., de Candia, P., and Russo, T. (1998). The Fe65 adaptor protein interacts through its PID1 domain with the transcription factor CP2/LSF/LBP1. J. Biol. Chem. 273, 20128-20133. doi:10.1074/jbc.273.32. 20128

Zhang, Y. W., Wang, R., Liu, Q., Zhang, H., Liao, F. F., and Xu, H. (2007). Presenilin/gamma-secretase-dependent processing of beta-amyloid precursor protein regulates EGF receptor expression. Proc. Natl. Acad. Sci. U.S.A. 104, 10613-10618. doi:10.1073/pnas.0703903104

Zhou, L., Wei, C., Huang, W., Bennett, D. A., Dickson, D. W., Wang, R., et al. (2013). Distinct subcellular patterns of neprilysin protein and activity in the brains of Alzheimer's disease patients, transgenic mice and cultured human neuronal cells. Am. J. Transl. Res. 5, 608-621.

Zhuravin, I. A., Dubrovskaya, N. M., Vasilev, D. S., Tumanova, N. L., and Nalivaeva, N. N. (2011). Epigenetic and pharmacological regulation of the amyloiddegrading enzyme neprilysin results in modulation of cognitive functions in mammals. Dokl. Biol. Sci. 438, 145-148. doi:10.1134/S001249661103015X

Conflict of Interest Statement: The authors declare that the research was conducted in the absence of any commercial or financial relationships that could be construed as a potential conflict of interest.

Received: 15 October 2013; accepted: 09 December 2013; published online: 23 December 2013.

Citation: Grimm MOW, Mett J, Stahlmann CP, Haupenthal VJ, Zimmer VC and Hartmann $T$ (2013) Neprilysin and A $\beta$ clearance: impact of the APP intracellular domain in NEP regulation and implications in Alzheimer's disease. Front. Aging Neurosci. 5:98. doi: 10.3389/fnagi.2013.00098

This article was submitted to the journal Frontiers in Aging Neuroscience.

Copyright (c) 2013 Grimm, Mett, Stahlmann, Haupenthal, Zimmer and Hartmann. This is an open-access article distributed under the terms of the Creative Commons Attribution License (CC BY). The use, distribution or reproduction in other forums is permitted, provided the original author(s) or licensor are credited and that the original publication in this journal is cited, in accordance with accepted academic practice. No use, distribution or reproduction is permitted which does not comply with these terms. 